DANIEL TOBIAS ATHIAS

\title{
Regulação e royalties de minério e petróleo: estudo comparado entre Brasil e Estados Unidos
}

Dissertação de Mestrado

Orientador: Professor Associado Fernando Facury Scaff

UNIVERSIDADE DE SÃO PAULO

FACULDADE DE DIREITO

São Paulo-SP

2018 
DANIEL TOBIAS ATHIAS

\title{
Regulação e royalties de minério e petróleo: estudo comparado entre Brasil e Estados Unidos
}

\begin{abstract}
Dissertação apresentada à Banca Examinadora do Programa de Pós-Graduação em Direito, da Faculdade de Direito da Universidade de São Paulo, como exigência parcial para obtenção do título de Mestre em Direito, na área de concentração de Direito Econômico, Financeiro e Tributário, sob a orientação do Professor Associado Fernando Facury Scaff.
\end{abstract}

UNIVERSIDADE DE SÃO PAULO

FACULDADE DE DIREITO

São Paulo-SP

2018 
BANCA EXAMINADORA

Fernando Facury Scaff 
À minha família e meus amigos, as pessoas que tiveram de arcar com a minha ausência. 


\section{AGRADECIMENTOS E DÍVIDAS}

Um indivíduo assume o compromisso de produzir um texto escrito com um único propósito: que seja lido, por quem quer que seja. Apesar dos medos, receios e apreensões (dentre outros termos aplicáveis) das críticas que poderão ser apresentadas e a eterna relutância de "liberar" um texto, ainda assim se deseja o compromisso de leitura de alguém do público. (In)felizmente o público é sempre pequeno, o que, de forma menos apreensiva, reduz as críticas, porém também reduz as possíveis instâncias de leitura.

Ou seja, o ofício de escrever ${ }^{1}$ tem aspecto nitidamente público ou voltado para o público, e embora se possa afirmar que o autor escreve para si, ele também escreve para a sociedade.

Contudo, o ofício de escrever é uma atividade individual e solitária, envolvendo reflexões internas do autor com os textos que leu e suas ideias, e principalmente como isso se traduz nos parágrafos que refletirão justamente esse raciocínio. Não se pode, assim, se socorrer de reflexões de terceiros, pois ao fim terá de ser produzido um texto assinado pelo autor.

A atividade acadêmica de pós-graduação clama por um texto e esssa necessidade terá de ser saciada, bem ou mal. ${ }^{2}$

Assim, não tenho receio em declarar que o texto que segue não foi apenas escrito para mim, mas para a comunidade acadêmica, na expectativa de que algum interessado, em algum momento da história, pegue o texto e dele possa extrair algo que lhe seja útil, nem que seja para uma nota de rodapé ou uma frase de crítica. Embora tenha sido laborioso, o texto sempre poderia ser melhor, mas ele reflete nitidamente o melhor que pode ser produzido no atual momento acadêmico do autor. Autocríticas com certeza existem, mas há consciência das limitações temporais e acadêmicas do momento.

\footnotetext{
${ }^{1}$ Não me senti à vontade em adotar a expressão ofício do verso, do livro do mesmo nome de Jorge Luis Borges, pela disparidade entre os textos, então o adaptei sutilmente.

2 Como bem destaca Winston Churchill: "Escrever um livro é uma aventura. No início, é um brinquedo, depois um divertimento. Então ele se torna uma amante, vira um dominador, se transforma em tirano e, no último estágio, quando se está quase acostumado com a servidão, mata-se o monstro e se o atira ao público." (CHURCHILL, Winston. A sutileza bem-humorada de Winston Churchill: suas grandes tiradas... Organizado por Richard Langworth; tradução de Joubert de Oliveira Brízida. Rio de Janeiro: Odisseia, 2012. p. 113).
} 
Sobre essas reflexões, encantou-me o prefácio preparado por Daniel Raymond ao seu livro Thoughts on political economy, valendo uma citação que, embora longa, serve de algum conforto para autores que ainda estão produzindo seu primeiro trabalho acadêmico de maior fôlego (peço licença aos leitores para citar o original em inglês para que nada se perca na tradução):

\begin{abstract}
The following sheets were written to please myself - my principal object in writing them, was employment. The public has not seen fit to give me constant employment in my profession otherwise this book had never been written. [...] I fear I can plead nothing which the public will think satisfactory - I cannot avail myself of that stale excuse, "the solicitation of friends," for no person, save the printer, ever saw the book in manuscript, and of course they would not have advised me to publish it. Whether it would have been possible to obtain their solicitation or not, is more than I can say, as I was afraid to make the attempt, lest I should get discouragement instead of solicitation. The best excuse me excuse I can allege for publishing, is, that it pleased me to do so, and one feels a sort of satisfaction in doing as he pleases, without consulting any one. [...] I have no excuse or apology to make for the imperfections of the performance. It is as perfect as I could make it, in the time and with the materials I possessed; although for less perfect that it ought to be. ${ }^{3}$
\end{abstract}

A citação reflete vários dos anseios que tive no preparo desta dissertação, com as devidas ressalvas, naturalmente. A partir dessas reflexões, gostaria de iniciar os meus agradecimentos.

Durante esta etapa do mestrado tive amplo e irrestrito apoio do meu orientador, o Professor Fernando Facury Scaff, que, além de ser uma reconhecida autoridade no tema abordado, leu, releu, discutiu, corrigiu, orientou e, mais importante, se mostrou paciente com o amadurecimento do texto e das discussões desenvolvidas. Apesar das críticas acirradas e diretas, o Professor Scaff sempre esteve disponível para corrigir os possíveis equívocos que estavam sendo cometidos (os erros que persistem são de minha culpa) e acompanhar sua evolução. Eu genuinamente o agradeço pelo apoio e pela orientação.

Aos queridos Fernando e Denise Scaff, agradeço pela acolhida em terras estrangeiras.

Naturalmente, nada desse trabalho seria possível sem o apoio da minha família. Perdoem-me pai, mãe, Arianne, Jordana, Victor, Rafael, Maria Luisa, Fabrício e Marcos pela distância, tanto física quanto emocional, e as inúmeras datas comemorativas e não

\footnotetext{
${ }^{3}$ RAYMOND, Daniel. Thoughts on political economy: in two parts. Baltimore: Fielding Lucas Junior, 1820.
} 
comemorativas em que não pude estar presente. Embora ausente, sabia que todos estavam comigo e me acompanhando. A saudade é imensa e espero que compreendam. A todos, os meus agradecimentos.

Em relação aos amigos, temo esquecer nomes daqueles cuja ajuda ou apoio foi inestimável. Farei uma tentativa, com certeza deficiente e falha, de citar aqueles que me vêem a memória: Alexandre, Camila, Danielle, Felipe, Francisco, Gabriel, Gustavo, Isabela (especialmente pela leitura e revisão), Laercio, Leonardo, Marcela, Ricardo e Victor. De qualquer forma, saibam que estou ciente de todos os finais de semana ausentes, mensagens não respondidas, desculpas inventadas, viagens e confraternizações desmarcadas e quaisquer outros eventos em que não me senti à vontade para participar, enquanto pesava sobre mim o peso deste trabalho. Farei o meu melhor para compensar a todos por essa ausência.

Agradeço às minhas duas famílias profissionais, os escritórios Silveira, Athias, Soriano de Mello, Guimarães, Pinheiro e Scaff Advogados e Grinberg Cordovil Advogados. Ambos incentivam suas equipes a aprofundarem constantemente seus conhecimentos acadêmicos, sendo compreensivos quanto às horas afastadas do trabalho, em compromissos acadêmicos.

Cabe um último agradecimento nominal e especial a Luisa, a pessoa que acompanhou mais de perto o anseio da produção do texto. Obrigado pela paciência, pelo carinho e pela torcida. O sofrimento foi compartilhado e espero que possa lhe retribuir.

A todos que tiveram alguma participação neste trabalho, cientes ou não, agradeçolhes pela troca de experiência que certamente o enriqueceu.

Registro que meus agradecimentos são uma verdadeira confissão de dívida e espero que possa lhes retribuir ao menos com minha presença "mais presente". Infelizmente, o tempo que passou não se recupera, mas me esforçarei em desfrutar o que nos restar com todos. 
All hopen abandon, ye who enter in!

Dante Alighieri (Divine comedy - Inferno)

The wheel is come full circle; I am here.

William Shakespeare (King Lear) 


\section{RESUMO}

ATHIAS, Daniel Tobias. Regulação e royalties de minério e petróleo: estudo comparado entre Brasil e Estados Unidos. 2018. 252 p. Dissertação (Mestrado em Direito) Faculdade de Direito da Universidade de São Paulo, São Paulo, 2018.

O objetivo desta dissertação é analisar certos aspectos da relação de dois Estados distintos, Brasil e Estados Unidos, com seus recursos minerais e petrolíferos, com ênfase em questões regulatórias da exploração e financeiras, a partir da instituição de royalties. Antes de efetuar qualquer comparação, contextualizam-se os critérios a serem analisados, principalmente a partir da sua formação histórica, inclusive com foco na terminologia adotada por cada um, evitando-se a comparação de institutos jurídicos que não necessariamente são equivalentes, ou, ao menos, destacando quais as distinções relevantes. Apresenta-se inicialmente uma visão da política econômica dos recursos minerais de cada Estado e a formação histórica dos seus regimes de propriedade e acesso para fins de exploração. Em seguida, descreve-se o surgimento dos royalties em cada país e a justificativa deles, além do arcabouço jurídico vigente que regula essa receita. Definida a receita de royalties, discute-se a forma como essa receita é partilhada entre os entes federativos internos de cada Estado, delineando como a formação do federalismo nos países e o federalismo fiscal afetaram o rateio de receitas da exploração minerária e petrolífera. Por fim, tecem-se breves comentários sobre o regime jurídico de uso (gasto) dos royalties, as restrições vigentes e os objetivos a serem perseguidos. Visa-se a demonstrar que há semelhanças entre os países, apesar de terem atribuído papéis distintos para a exploração e a receita de recursos minerais e petrolíferos em suas economias.

Palavras-chave: Royalties. Federalismo. Federalismo fiscal. Regimes de propriedade. Brasil. Estados Unidos. 


\begin{abstract}
ATHIAS, Daniel Tobias. Regulation and royalties from minerals and oil: a comparative study of Brazil and the United States. 2018. 252 p. Dissertation (Master in Law) Faculdade de Direito da Universidade de São Paulo, São Paulo, 2018.

The objective of this dissertation is to analyze certain aspects of the relationship between two different nations, Brazil and the United States, and their mineral and oil resources, with emphasis on regulatory issues of exploration and financial issues concerning the collection of royalties. Before carrying out any type of comparison, the criteria to be analyzed will be put into context, mainly from their historical formation, including the terminology utilized by each country in order to avoid comparing legal institutions that are not necessarily equal, or, at the very least, relevant distinctions will be highlighted. Initially, the political economy's vision concerning mineral resources for each country will be presented, as well as the historical formation of proprietary regimes of said resources and access for exploration. Then, the emergence of royalties will be addressed, alongside its justification and the legal framework in force that regulates this revenue. Having set forth royalties, the criteria for revenue sharing between internal federal entities will be explained, and how federalism and fiscal federalism in each country affected said criteria for revenue from exploring minerals and oil. Finally, brief comments on the legal framework for use of royalty revenue, restrictions and goals in spending will be provided. The purpose is to demonstrate how there are similarities between both countries, albeit the fact that each chose to attributed different roles to the exploration and revenue from minerals and oils in their economy.
\end{abstract}

Keywords: Royalties. Federalism. Fiscal Federalism. Proprietary regimes. Brazil. United States of America. 


\section{SUMÁRIO}

INTRODUÇÃO

1 REGULAÇÃO DO ACESSO AOS RECURSOS MINERAIS E PETROLÍFEROS ....... 19

1.1 Panorama geral das políticas industrial e de desenvolvimento.....................................20

1.2 Importância das atividades minerária e petrolífera para o Estado .................................. 34

1.2.1 Nacionalização dos recursos minerais e a exploração em prol do interesse público.. 43

1.3 Regimes de acesso e propriedade de recursos minerais não renováveis ........................45

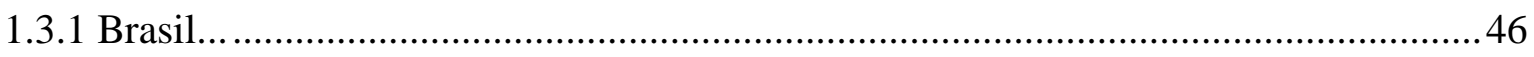



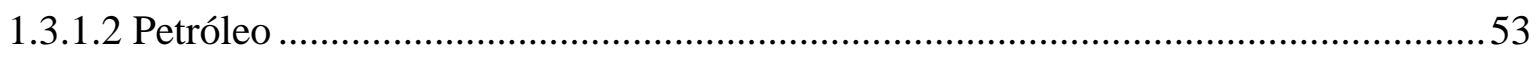

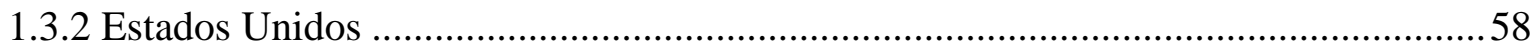

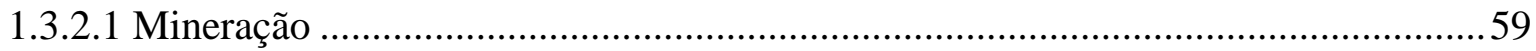

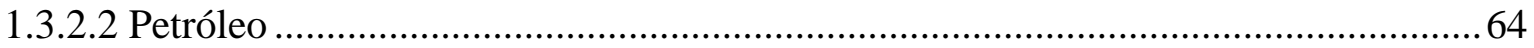

1.4 Análise das escolhas estatais da gestão e regulação do acesso aos recursos minerais

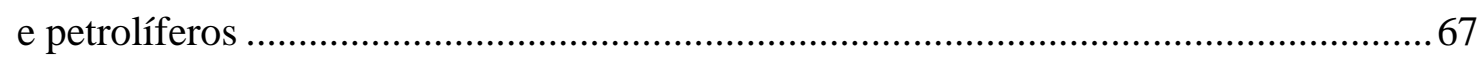

2 ROYALTIES NA EXPLORAÇÃO DE RECURSOS MINERAIS ...................................73

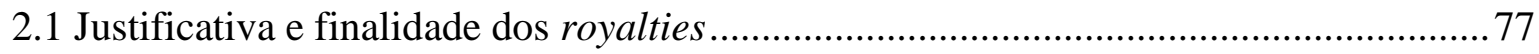

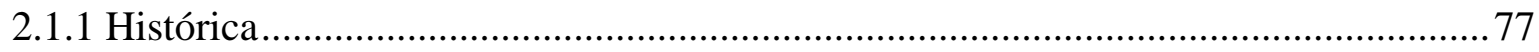

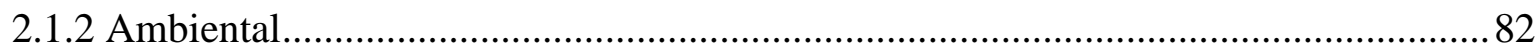

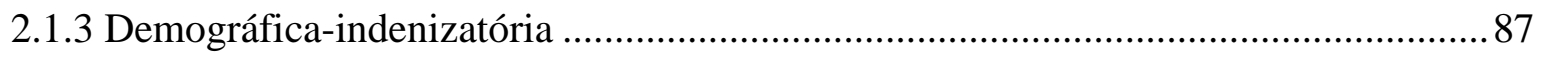

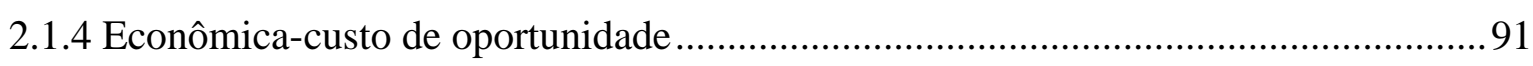

2.2 Royalties na exploração de recursos minerais e petrolíferos ........................................95

2.2.1 Incidência e previsão legal dos royalties (stricto sensu) .........................................96

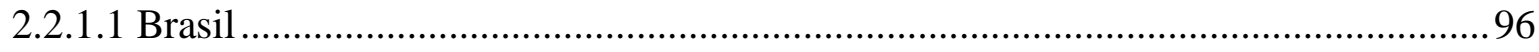

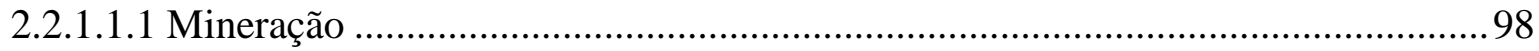

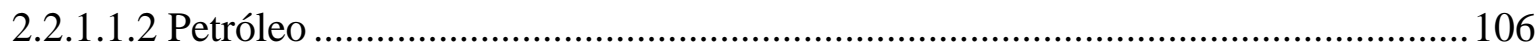

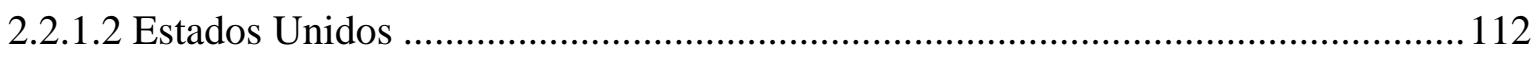

2.2.1.2.1 Mineração ................................................................................................. 113

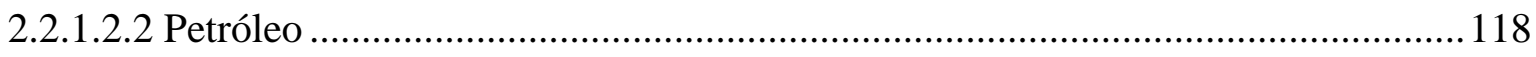

2.3 Semelhanças e diferenças na cobrança de royalties ............................................... 125 
3 FEDERALISMO PATRIMONIAL E RATEIO DE RECEITAS MINERAIS

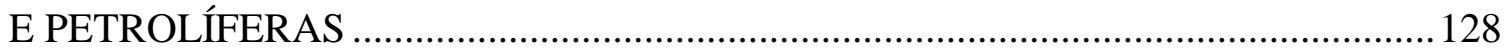

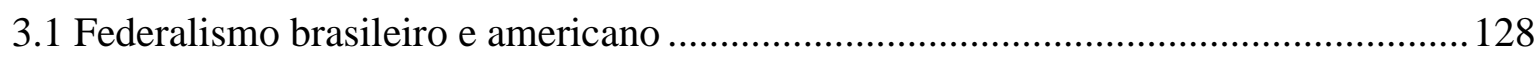

3.2 Federalismo ambiental: interesses nacionais e impactos locais da exploração ........... 144

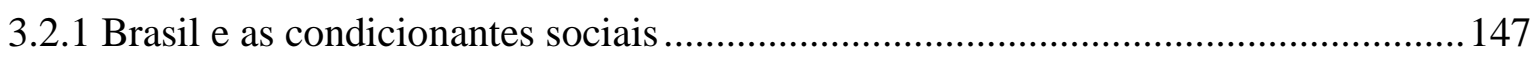

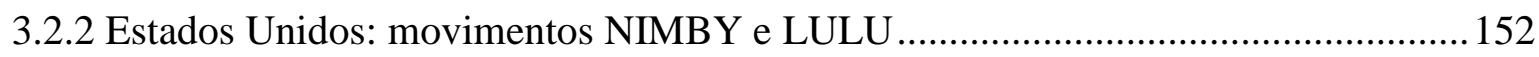

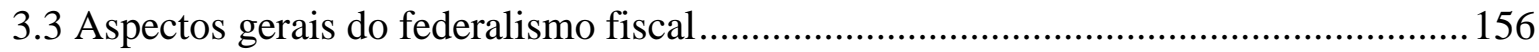

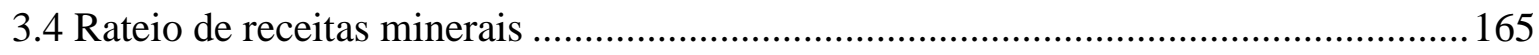

3.4.1 Rateio de receitas da exploração mineral stricto sensu ....................................... 167

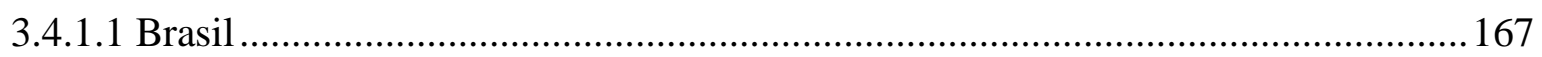

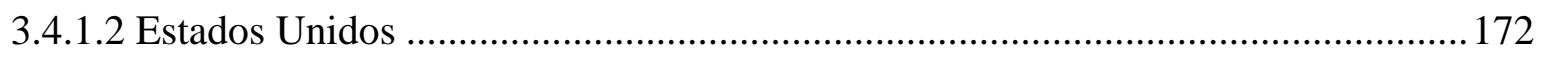

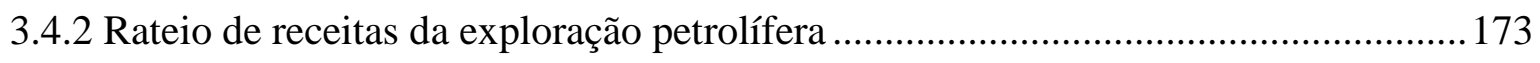

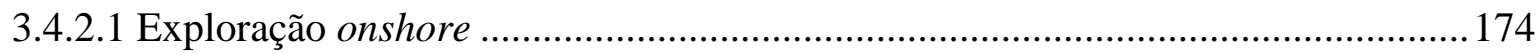

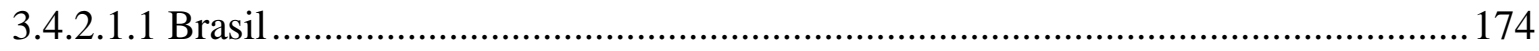

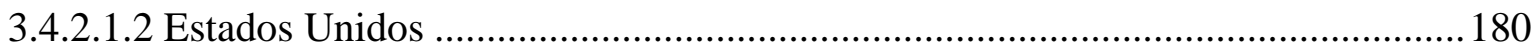

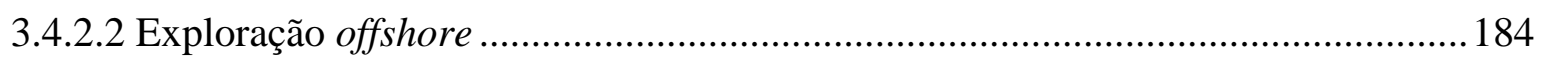

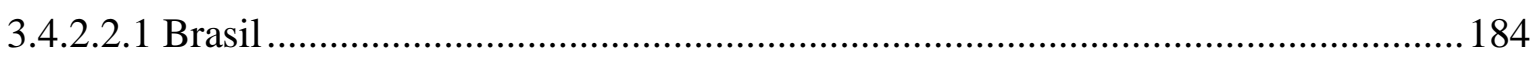

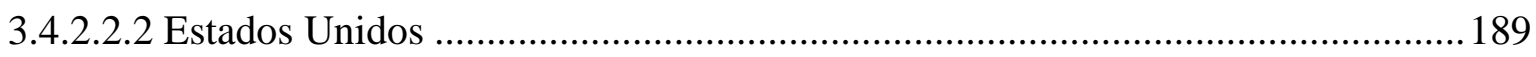

3.5 Análise comparativa do federalismo ambiental, fiscal e patrimonial .......................... 191

4 USO DAS RECEITAS PÚBLICAS MINERAIS E PETROLÍFERAS ........................197

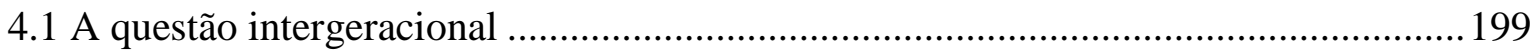

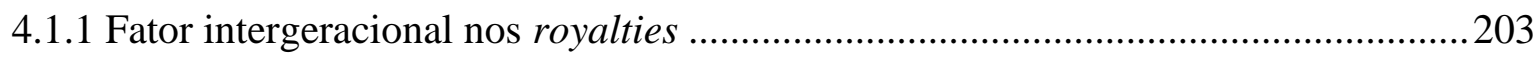

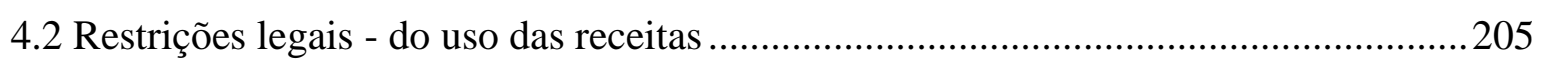

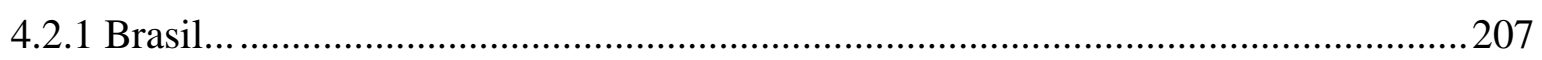

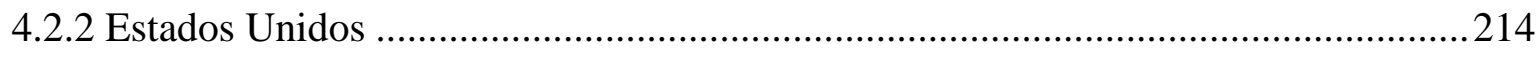

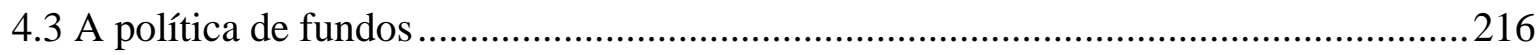

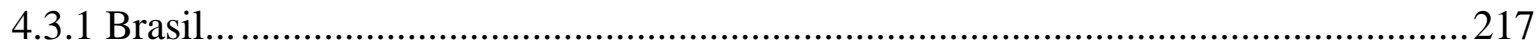

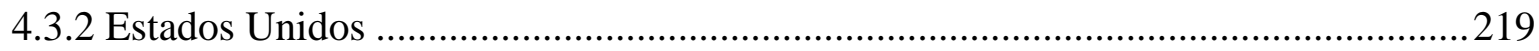

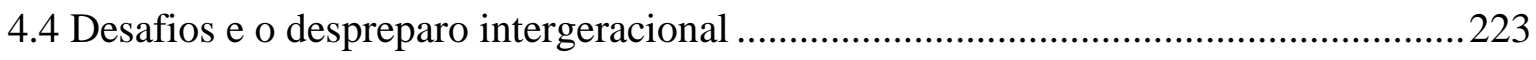

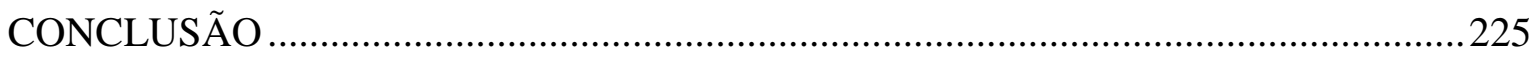

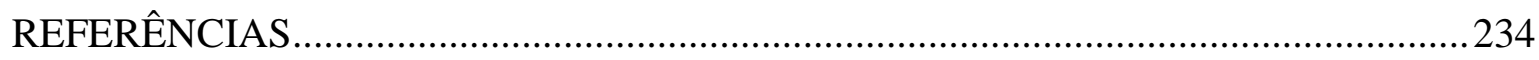




\section{INTRODUÇÃO}

A relação entre Estado, sociedade e recursos naturais não renováveis é repleta de pontos controversos, cuja abordagem pode se dar a partir de diversas perspectivas e vieses, seja focando em questões ambientais (licenciamento dessas atividades), financeiras (royalties e sua distribuição), econômicas (regimes regulatórios de exploração), constitucionais (competências federativas em relação à exploração) e até criminais (impactos sociocriminais advindos da instalação de parques minerários em regiões subdesenvolvidas).

O propósito deste trabalho é apresentar ao leitor um panorama amplo e geral sobre questões específicas da exploração de recursos minerais e petrolíferos no Brasil e nos Estados Unidos, comparando institutos jurídicos de ordenamentos distintos. O pano de fundo da análise apresenta como cada país enfrentou desafios semelhantes na exploração de seus recursos, tais como segurança energética, abastecimento interno e soberania.

Naturalmente, alguns detalhes não poderão ser abordados de forma exaustiva, dada a amplitude do tema, e terão de ser melhor tratados em pesquisas desenvolvidas posteriormente.

Focar-se-á, principalmente, a estrutura jurídica de uma das receitas estatais (i.e., government take) cobradas dessas atividades, os royalties, e aspectos regulatórios da exploração quanto ao acesso a esses recursos minerais e petrolíferos.

Assim, a trajetória do trabalho apresentará uma intersecção entre história, evolução legislativa, ordenamento jurídico vigente e desafios atuais sobre quatro principais pontos, títulos dos capítulos que seguem: (i) regulação do acesso aos recursos minerais; (ii) royalties na exploração de recursos minerais; (iii) federalismo patrimonial e rateio de receitas minerais e petrolíferas; e (iv) uso das receitas públicas minerais e petrolíferas. Esses pontos darão uma visão ampla de como o Brasil e os Estados Unidos se relacionam com a exploração dos seus recursos minerais e petrolíferos, bem como os consequentes desdobramentos dessa atividade econômica e a arrecadação, distribuição e uso dos royalties. 
Considerando que o objeto do trabalho é comparativo, cabe apresentar algumas das justificativas acerca do objeto de estudo. Isto é, por que se optou por fazer um estudo comparativo e por que os Estados Unidos foram escolhidos como objeto de comporação? A escolha não foi aleatória. Ambos os países, além de reunirem condições passíveis de comparação, têm papel central na exploração e consumo de recursos minerais e petrolíferos no mundo, com soluções jurídicas distintas. A intenção foi justamente eleger um país que também teria algum tipo de protagonismo na exploração de recursos naturais, seja pela extração, seja pelo consumo.

Primeiro, ambos os países adotaram forte atuação estatal na busca de seu desenvolvimento, principalmente em setores de infraestrutura, não se podendo classificar os Estados Unidos como uma nação direcionada unicamente pelo setor privado (e pela sociedade civil), com ausência (ou mera supervisão neutra) do Estado. A diferença está no critério temporal eleito pela análise: não se pode olhar a fotografia atual de cada país, é preciso assistir ao filme e tentar apontar como se alcançou a atual condição, Brasil como país em desenvolvimento e Estados Unidos como desenvolvido. Embora nos Estados Unidos a tendência seja de atribuir à esfera privada poder decisório sobre a alocação econômica, isso não significa que não houve e não haverá atuação pública de direcionamento. ${ }^{4}$

Curiosamente, esse não é o senso comum acerca de como ambos os países enfrenta(ra)m seus problemas e preocupações em relação ao desenvolvimento econômico e à redução de desigualdades regionais e da pobreza ${ }^{5}$. É preciso ampliar o espectro temporal,

\footnotetext{
${ }^{4}$ Esse é de certa forma o raciocínio apresentado por Ha-Joon Chang, ao afirmar que as atuais best practices defendidas por países desenvolvidos para países em desenvolvimento não constituem as ferramentas por eles utilizadas. Nas suas palavras: "As políticas usadas para chegar onde eles [os países agora desenvolvidos] estão agora - ou seja, políticas industrial, comercial e tecnológica ativas - são precisamente as que eles dizem que os países em desenvolvimento não devem usar por causa de seus efeitos negativos sobre o desenvolvimento econômico." (CHANG, Ha-Joon. Chutando a escada: a estratégia do desenvolvimento em perspectiva histórica. Tradução de Luiz Antônio Oliveira de Araújo. São Paulo: Unesp, 2004. p. 127). No mesmo sentido, Reginaldo C. Moraes e Maitá de Paula e Silva: "Contudo, como dissemos, até mesmo análises sofisticadas insistem em minimizar essa intervenção do comando estatal no desenho do modelo socioeconômico, em particular quando o discurso se dirige a países em desenvolvimento como uma 'lição de história'. É conhecida a sentença de List segundo a qual os portavozes dos países industrializados de sua época - mormente a Inglaterra - operavam uma prestidigitação intelectual: utilizavam políticas de desenvolvimento e em seguida as escondiam. Subiam por uma escada e, alcançado o andar superior, lançavam-na longe, para que não fosse mais utilizada." (MORAES, Reginaldo Carmello Corrêa de; SILVA Maitá de Paula e. O peso do Estado na pátria do mercado: os Estados Unidos como país em desenvolvimento. São Paulo: Unesp, 2013. p. 2-3).

5 "Os Estados desenvolvem políticas públicas, dentre outros objetivos, para proteger determinados grupos. Essa proteção a esses grupos vulneráveis se desenvolve quer tendo em vista a fragilidade de determinados
} 
abrangendo o período em que ambos se encontravam em fase de desenvolvimento (ou eram subdesenvolvidos). Há, de fato, políticas econômicas de forte atuação estatal.

O segundo motivo da seleção se funda no fato de os Estados Unidos terem uma abundância de reservas petrolíferas e minerais, embora o setor extrativo não tenha papel central na economia (ao contrário da importância dada no Brasil). Ademais, e como será esmiuçado, esse país foi historicamente ator central na indústria petrolífera, seja como produtor, seja como consumidor, podendo voltar a ser um dos produtores principais de hidrocarbonetos, a partir da exploração do folhelho. Em resumo, ambos os países possuem reservas significativas que poderão ser exploradas e optaram por trilhar caminhos distintos, reforçando que não é um destino aprioristicamente definido.

O terceiro motivo é que ambos os países elegeram a estrutura federativa para a distribuição de competências e a partilha de receitas. Nos dois casos se constata uma tendência pela centralização de poderes na esfera federal, principalmente devido aos desafios atuais que clamam por uma atuação coordenada. A distribuição de competências interna permite verificar como os países lidaram com a propriedade dos recursos minerais, os entes competentes para autorizar a exploração e as reações das comunidades locais diretamente afetadas. Apesar de distintos, ambos os países lidam com fortes reações de comunidades locais afetadas pelas atividades exploratórias, havendo um conflito entre interesses nacionais da exploração e os impactos locais.

Por fim, a formação histórica de cada país como colônia influenciou significativamente a relação dos Estados com seus recursos naturais, no que tange aos regimes de propriedade, cabendo avaliar como cada um lidou com a independência de seus respectivos colonizadores e como estruturaram juridicamente a propriedade de recursos que antes pertenciam às Coroas.

\footnotetext{
grupos, quer tendo em vista a necessidade de proteção (como as pessoas com deficiência ou os idosos) ou quer ainda diante do interesse do Esado em determinado objetivo, como, por exemplo, incluir determinado grupo que está abaixo de um patamar mínimo nacional de alimentação ou um grupo que necessita de amparo para regularizaçao de suas terras. No caso do Brasil, a Constituição Federal protege diversos grupos pelos mais variados motivos específicos, tendo como pano de fundo a sua fragilidade diante de outros grupos." (ARAUJO, Cíntia Rejane Möller de; ARAUJO, Luiz Alberto David. Intervenção: as crises econômicas atuais, os cortes de orçamento, os grupos vulneráveis e o exercício democrático. In: POMPEU, Gina; CARDUCCI, Michelle; ARAUJO, Luiz Alberto David (Orgs.). A constituição à prova da crise financeira internacional. Florianópolis: Empório do Direito, 2017. p. 351).
} 
Os motivos apresentados são tanto as razões pelas quais se elegeu os Estados Unidos, quanto os fatores que possibilitaram essa comparação. Neste ponto, cabe destacar que este trabalho não tratará das tradições das "famílias jurídicas” de cada país em relação ao common law e civil law e como se desenvolveu o ordenamento jurídico de cada um. Para fins deste trabalho, esta análise não será necessária, vez que a maioria dos temas tratados parte de legislação codificada. Não obstante, em alguns casos, onde se fará necessário, decisões relevantes dos Estados Unidos serão citadas. De qualquer forma, parte-se do pressuposto de que o leitor tenha uma noção geral da distinção, o que ora será mais do que suficiente. ${ }^{6}$

Cabe o registro de que, como esperado, cada país possui uma trajetória histórica própria e sistemas jurídicos distintos, o que pode tornar um exercício comparativo, na melhor das hipóteses, difícil, e, na pior, impossível, pois a forma de atuação do Estado é tanto fruto quanto fator de influência do seu atual momento. Em outras palavras, o ordenamento jurídico é tanto causa como efeito de alterações ao longo do tempo da relação entre Estado e recursos naturais.

Tentar-se-á evitar cair na fácil armadilha de apenas se debruçar sobre a existência ou não de royalties em cada país, quais são as alíquotas aplicadas e como são distribuídas as receitas, dentre outros pontos que, apesar da sua utilidade, não dariam uma visão completa sobre a relação entre Estado e recursos naturais, o que se entende essencial. Ou seja, não basta compreender a existência ou não desse tipo de cobrança e quais as normas em vigor, mas como ela se deu, por que ela existe e por qual motivo as respectivas legislações se encontram naquele estado. A mera nomenclatura de royalties também resultaria em possíveis confusões, ante a existência de royalties privados e públicos em ambos os países, embora com nomes diferentes - royalties privados (Estados Unidos) e direito dos superficiários (Brasil). Além da barreira da linguagem, seria necessário verificar se as palavras significam a mesma coisa em ambos os países, o que nem sempre é o caso.

\footnotetext{
${ }^{6}$ Sobre a questão, vide: DAVID, René. Os grandes sistemas do direito contemporâneo. Tradução de Hermínio A. Carvalho. 5. ed. São Paulo: Martins Fontes, 2014. p. 445 e ss.
} 
Apresentado o contexto e o objetivo do presente trabalho, bem como indicadas as ressalvas de análise, o resultado desta pesquisa se desenvolverá a partir de quatro capítulos principais, cada qual tratando de um tema geral, apresentando as nuances de seu objeto.

O primeiro capítulo tratará do tema mais sensível relativo à exploração de recursos minerais e petrolíferos, a propriedade desses recursos. Isto é, se o país adotou um regime de propriedade pública com exploração pública, de propriedade pública e exploração privada ou um sistema misto de propriedade privada e pública; os desenhos, a rigor, são ilimitados. A sensibilidade da propriedade emana da sua relação com a soberania de um Estado, tendo a nacionalização, por exemplo, sido tema de mais de uma resolução da Organização das Nações Unidas (ONU), que visavam a fortificar a posição dos Estados na liberdade de dispor de seus recursos minerais. Se, como destacado por um ex-secretário americano, "energy security is national security", a propriedade e as formas de acesso a esses recursos minerais são pontos basilares do controle estatal de uma atividade que lhe é tão essencial.

No segundo capítulo, será esmiuçado como são cobrados os royalties em cada país, notadamente as justificativas encontradas para essa cobrança e as finalidades para as quais essas receitas deveriam servir. Nesse capítulo, verificar-se-ão as dificuldades dos Estados Unidos em adaptar seu ordenamento jurídico à atualidade, dada a inexistência de previsão de royalties para a mineração de forma geral e as consequências disso, e os supostos esforços modernizadores da indústria minerária no Brasil, a partir de reformas dos marcos regulatórios.

No terceiro capítulo, novamente será dado destaque às questões históricas de ambos os países em relação à formação da estrutura federalista adotada. Para além de questões de rateio das receitas minerais e as concentrações existentes em ambos os países dessas receitas, o que pode significar, na prática, a redução do seu potencial transformador pela sua dispersão ou uso por entes com menor poder para tanto, cumpre destacar comentários tecidos acerca do federalismo ambiental em ambos os países e a relação entre interesses nacionais e impactos locais da exploração.

Por fim, o último capítulo apresentará as limitações instituídas ao uso das receitas minerais arrecadadas, ao cotejar os possíveis efeitos negativos oriundos de um uso 
descontrolado de receitas minerárias e petrolíferas, bem como a necessidade de se observar critérios intergeracionais, notadamente pelas especificidades da exploração de recursos naturais não renováveis.

Cada capítulo também terá um breve item ao seu final, no qual serão apresentados comentários sobre a comparação efetuada entre os dois países.

Cabe aqui destacar que um dos principais desafios enfrentados neste trabalho, feito a distância de um dos países objeto de comparação, foi justamente o acesso à informação, o que é facilitado no Brasil, a partir de uma legislação federal codificada. O ordenamento jurídico americano, pela sua estrutura e autonomia estadual, dificultou, por diversas vezes, a localização de dados e legislações específicas.

É preciso destacar que este trabalho não parte de uma noção preconcebida de que ordenamentos jurídicos estrangeiros são melhor estruturados do que o brasileiro e sequer visa a defender transplantes jurídicos e modelos one size fits all. O objetivo não é partir de uma crença de que o Brasil é menos desenvolvido, capacitado ou sofisticado e que o objeto visa à subordinação e traçar uma hierarquia. Não se quer fazer uma leitura acrítica de qualquer ordenamento jurídico.

A questão é apresentar a formação de cada país e como os desafios semelhantes que ambos enfrentaram resultaram em soluções jurídicas distintas ou semelhantes. 


\section{CONCLUSÃO}

O objetivo desta dissertação foi comparar países que seriam, pela percepção do público, incomparáveis. Os objetos de análise, alguns diriam, seriam muito destoantes para permitir qualquer tipo de exame efetivo, pois a atuação do Estado em um deles seria muito diferente da do outro, um estaria focado, talvez até excessivamente, no desenvolvimento do setor primário da exploração de recursos minerais, e o outro teria papel geopolítico relevante no mundo em relação a esses recursos naturais, e isso sem sequer entrar no mérito da família jurídica de cada país.

Entende-se que este trabalho conseguiu avançar um pouco no sentido de quebrar essa crença mal posta. Existem mais pontos de contato e de semelhança do que a maioria das pessoas tem consciência ou do que gostariam de acreditar, pois assim se pode manter, inclusive, uma visão não contestada sobre falsas verdades. Igualmente, muitos ficarão surpresos em saber que nosso ordenamento jurídico não é pior do que o seu objeto de comparação, e ambos possuem falhas e enfrentam desafios próprios.

Antes de apresentar as conclusões gerais, vale recapitular alguns pontos dos capítulos acima.

O primeiro capítulo visou a afastar a crença mantida por muitos que o Estado norteamericano partiu de um livre mercado ou livre cambismo extremo, apresentando uma trajetória histórica sobre as medidas de atuação da esfera pública para incentivar o desenvolvimento, aproximando-o do caso brasileiro. Observou-se que ambos os países, no afã de se desenvolver, lançaram mão de políticas hoje vistas como ortodoxas e inadequadas. O motivo para tanto é ressaltar como ambos os Estados estão atentos a questões que lhe são estratégicas economicamente, passando então à relação que ambos tiveram com seus recursos minerais e petrolíferos, desde as suas origens coloniais.

Os Estados Unidos são um caso deveras peculiar, em razão da possiblidade de ampla apropriação privada de recursos minerais hardrock. Essa mera constatação traz à tona o fato de que a lei é amplamente criticada, embora se tenha dificuldades extremas em alterar um regime tão longevo (nem sequer para instituir royalties). Consciente das 
dificuldades que enfrentou na regulação dos recursos minerais (stricto sensu), diversos outros recursos naturais foram sendo posterior e paulatinamente destacados desse regime geral. Com a adoção do regime de acessão (Mineral Leasing Act) foi possível garantir algum nível de controle, bem como ordenar a exploração. O regime americano é diametralmente oposto ao brasileiro, no qual, embora tenha vigorado por breve período um regime de apropriação privada, a regra foi quase sempre de propriedade pública, com exploração por empresa pública monopolista (no caso do petróleo) e/ou depois por agentes privados por meio de autorização.

Curiosamente, e como destacado acima, a regulação da propriedade e do acesso seguiu uma ordem lógica: primeiro houve a valorização do recurso e a amplificação da atividade, para depois existir o interesse estatal em regulá-la. São exemplos os minerais nobres, como ouro e prata, que sempre tiveram algum tipo de controle, dado o seu valor para as Coroas. Ou seja, desde a descoberta do Brasil e dos Estados Unidos, havia regulação da disposição desses bens. A petrolífera viria bastante tempo depois (nos Estados Unidos primeiro e depois no Brasil), tendo despertado interesse a partir da mudança dos padrões de combustível e o amplo uso de hidrocarbonetos na Primeira Guerra Mundial. Houve consciência de que os regimes jurídicos então vigentes não eram adequados para tratar de um recurso tão estratégico.

No segundo capítulo levantaram-se os desafios enfrentados por esses países para garantir a arrecadação de valores justos, ao abrirem mão de patrimônio não renovável, considerando que as receitas oriundas da exploração de recursos minerais e petrolíferos são a principal fonte de arrecadação não tributária. No caso brasileiro, a cobrança de royalties é característica intrínseca da exploração minerária e petrolífera, cujos valores são impostos por legislação federal, não havendo previsão legal de o Estado abrir mão dessa receita. A questão interna na mineração sempre tratada com ajustes finos na base de cálculo, no momento da incidência, dentre outras formas de aumentar os valores a serem cobrados, tanto que a modernização do marco regulatório da mineração foi, na realidade, um projeto fiscalista visando a aumentar a arrecadação.

Apesar das críticas difundidas da apropriação quase gratuita de terras públicas pelo General Mining Act, sem qualquer contraprestação de royalties, verificou-se que apesar de diversas tentativas de mudança legislativa, não houve sucesso. Ou seja, desde a sua 
concepção, terras minerais estão sendo amplamente apropriadas e muitas vezes sequer para fins dessa atividade, e nada consegue ser feito para tentar reverter essa situação. No setor petrolífero, por sua vez, os americanos conseguiram evitar os contratempos e desafios enfrentados na mineração, reservando para si a propriedade do recurso, mas permitindo a exploração com o pagamento de uma contraprestação.

Uma das questões mais curiosas que se constatou foi a existência e utilização de regimes de partilha de produção nos Estados Unidos, sendo que, quando da discussão da implantação do novo regime para a exploração petrolífera das camadas do pré-sal e a proposta da partilha de produção, diversos críticos insurgiram contra o novo modelo. Argumentaram esses críticos que esse modelo traria insegurança jurídica, ante o bom funcionamento do regime de concessão, além de se tratar de uma invenção de países periféricos, que não poderia ser levada a sério. Embora o regime de partilha tenha sido descontinuado na esfera federal, ele continua sendo utilizado por alguns Estados, permitindo o recebimento de royalties como petróleo.

No terceiro capítulo, apresentaram-se noções gerais de federalismo, federalismo ambiental fiscal e patrimonial, isto é, como se relacionam os entes administrativos internos de ambos os Estados a partir da partilha de competências e fontes de receitas para cumprir com suas funções. Iniciou-se com um apanhado histórico sobre o desenvolvimento do federalismo americano, o qual teria servido de modelo para os demais países, embora essa afirmação também seja alvo de discordância.

Para além das diferenças apresentadas sobre a maior autonomia dos Estados e entes subnacionais, ao contrário do que ocorre na prática no Brasil, é relevante destacar a tendência centralizadora de poderes. Isso não decorre de um processo formal para aumentar o escopo de competência da esfera federal, mas da prática, dada a extensão dos problemas que estão se apresentando na atualidade, muitos dos quais requererem uma atuação centralizadora, nem que seja para fins de eficiência produtiva e alocativa. A partir desse movimento centrípeto, surgem desafios também de monta ambiental, no que foi denominado de federalismo ambiental.

Constatou-se que os países enfrentam problemas em coordenar e harmonizar interesses nacionais e locais, mais especificamente atividades de ampla utilidade nacional, 
cujos impactos são restritos a localidades específicas. Ao contrário de uma mera imposição das esferas federais, sem levar em consideração os interesses locais, o que se percebe é que essas comunidades estão se organizando para garantir que seus interesses sejam ouvidos. No caso, isso pode resultar tanto numa maior discussão ambiental de licenciamento, quanto no efetivo bloqueio da atividade. É necessário levar em consideração os interesses das comunidades afetadas, é fato, mas destaca-se também que bloqueios locais, ao menos nos Estados Unidos, dificultam uma política de infraestrutura coordenada nacionalmente.

O último ponto discutido nesse capítulo se refere à partilha das receitas de royalties, havendo tendência de concentrá-las nos Estados e Municípios onde ocorre a exploração. No Brasil, constata-se uma transição dessa concentração para um regime de distribuição mais ampla, o que é nítido no setor de exploração petrolífera, notadamente a partir do regime de partilha; na mineração, por sua vez, ainda há clara concentração nos locais onde o minério se encontra. Nos Estados Unidos, a distribuição é mais restrita ainda, pois no petróleo (lembrando que não há royalties federais minerais), as receitas são concentradas de forma dúplice, primeiro pela distribuição direta, e segundo pela distribuição para fundos que financiam projetos hídricos onde esses recursos se encontram, e somente uma pequena parcela é alocada ao Tesouro Nacional para uso irrestrito.

No quarto e último capítulo, veio à torna o despreparo de ambos os países para lidar com as consequências intergeracionais da exploração de recursos naturais não renováveis. Embora haja projetos cuja intenção seria prolongar os benefícios das receitas arrecadadas ao longo do tempo, seja pela economia, seja pelos gastos, isso não se traduziu de forma eficaz em posturas adequadas dos governos. Ou seja, embora existam fundos intergeracionais, eles não foram instituídos efetivamente ou os recursos foram esvaziados, como no caso brasileiro, ou, ainda os fundos que existem não estão sendo utilizados da melhor forma, vez que há transferência financeira direta aos cidadãos, como no Alasca. As regras jurídicas também não são suficientes.

Embora possa haver alguma diferença em relação aos instrumentos ou desenhos econômicos utilizados, é possível apontar, em relação ao objeto do trabalho, lógicas e formas de atuação comuns para organizar a exploração de recursos naturais não renováveis e alcançar o desenvolvimento, tais como necessidade de desenvolver uma infraestrutura interna, garantir a soberania energética e o abastecimento do mercado interno, preocupação 
com a soberania externa, participação do governo nessa atividade (em ambos os casos houve interesse de exploração estatal de petróleo) e a preocupação em garantir o mínimo de bem-estar aos cidadãos, na oferta de saúde e educação pública, por exemplo. Em ambos os países, embora em graus distintos, houve a compreensão de que o mercado e o desenvolvimento não são fenômenos estanques e que se manifestam em um vácuo, no qual apenas o setor privado seria protagonista: há forte correlação entre desenvolvimento e Estado.

Cabe, agora, concluir e apresentar as impressões finais, após a pesquisa realizada. Não se pretende fazer comentários de cunho subjetivo sobre qual ordenamento seria melhor ou pior, pois isso também dependeria de uma análise dos objetivos pretendidos pelo ordenamento desenhado e se eles cumprem essa função. A rigor, a criatividade normativa possibilitaria equiparar os efeitos, na prática, de dois ordenamentos distintos.

De qualquer forma, far-se-á uma avaliação com base em três eixos, cotejando-os com o que foi desenvolvido nos capítulos anteriores: (i) cobrança de valor justo pela exploração dos recursos não renováveis; (ii) distribuição ampla das receitas oriundas da exploração dos recursos minerais; (iii) uso adequado das receitas, para garantir observância de critérios intergeracionais.

Em relação ao primeiro ponto (“i”), chegou-se à conclusão, já antecipada na introdução, que o ordenamento jurídico brasileiro não é inferior ao americano, especialmente no que tange à gestão das receitas oriundas da exploração dos recursos minerais e petrolíferos. Apesar das críticas que possam ser feitas aos termos da legislação e a necessidade de seu aprimoramento, o Estado brasileiro se propõe a arrecadar algum valor pela exploração de seu patrimônio. Ou seja, um Estado que gera um patrimônio em prol de toda a nação, tenta garantir um retorno adequado à sociedade.

Esse retorno, de alguma forma implica um tipo de controle público da atividade, principalmente a partir de questões de propriedade e regulação do acesso. Caso a esfera pública possibilite uma exploração descontrolada, difícil seria garantir o retorno adequado à sociedade. Assim, a garantia do retorno se deu principalmente pelo fato de que os recursos minerais são propriedade pública que, caso seja explorada por agente privado, deve apresentar contraprestação por esse uso. 
Os Estados Unidos apresentam falhas no cumprimento do imperativo de garantir à sociedade um retorno adequado dos seus recursos. As falhas (referentes à mineração) são resultado da formação histórica do país e dos critérios e políticas de ocupação privada de território, garantindo à esfera privada propriedade ampla e irrestrita, inclusive dos recursos naturais. Em outras palavras, pecou-se, na medida que se abriu mão não só de recursos minerais sem contraprestação, mas também pela apropriação de terras públicas por valores ínfimos, tudo isso permitido pela legislação.

Quanto a esse ponto específico, é difícil não apresentar críticas ao Estado norteamericano, pois apesar da origem histórica de legislação tão longeva, não é adequado que isso se mantenha até hoje, quase 150 anos após a aprovação do General Mining Act. Essa paralisia legislativa não se deu, pelo que consta, de mera displicência, pois houve tentativas de alterar a legislação. Contudo nenhuma medida conseguiu avançar. As falhas foram corrigidas a partir da exploração petrolífera, momento em que se destacou a exploração desse recurso do regime geral, alocando-o a lei específica, com previsão expressa de cobrança de royalties.

Ante as falhas legislativas americanas e a não garantia de retorno à sociedade pela exploração dos recursos minerais do país (além da apropriação de terras públicas), a única afirmação possível é que o seu ordenamento jurídico é deficiente. No caso brasileiro, apesar dos problemas da legislação, há expressa previsão de cobrança ampla e irrestrita pela exploração dos seus recursos minerais (lato sensu).

O segundo eixo de análise eleito foi a distribuição das receitas arrecadadas pela exploração de recursos minerais. A importância dessa distribuição no País é garantir que não só os entes beneficiados pela sorte, ao terem recursos minerais no seu subsolo, sejam beneficiados. Isto é, se os recursos minerais pertencem a toda a sociedade, não seria adequada uma concentração excessiva em poucos agentes.

A análise dos Estados Unidos sob esse prisma é mais complicada, ao se considerar que existem recursos minerais e petrolíferos de propriedade federal e estadual, o que diferencia substancialmente as formas de distribuição, pois não se está tratando, a rigor, de um bem do país inteiro, gerido pela esfera nacional, mas sim de bem de ente subnacional, que é gerido em prol desse ente. 
De todo modo, em ambos os países se constata uma concentração direcionada para os locais onde ocorre a exploração, seja na forma de transferências diretas ou no uso de fundos, cujos principais beneficiados seriam os países onde ocorre a exploração. Ou seja, embora os royalties não tenham sido instituídos para compensar um determinado ente por danos ou para mitigar impactos ambientais, infere-se que o atual desenho da distribuição privilegia esses fatores.

No Brasil, a distribuição de royalties minerários é concentrada nos entes onde ocorre a exploração ou aqueles que seriam afetados por ela. Em relação aos royalties petrolíferos, tanto onshore quanto offshore, há uma distribuição mais ampla, valendo-se o ordenamento jurídico de fundos diversos para auxiliar na distribuição difusa dos valores arrecadados e observando critérios de desigualdades regionais. Nos Estados Unidos, os royalties petrolíferos onshore também apresentam uma distribuição rígida e voltada para os locais onde ocorre a exploração, e outra parcela significativa para fundos que financiaram projetos na região macropolítica onde ocorre a exploração. Na exploração offshore, por sua vez, apesar da concentração também nos Estados costeiros, há casos em que metade dos valores arrecadados é atribuída à União, cuja extensão e escopo de gastos mais amplos possibilitariam o benefício de toda a sociedade.

Ambos os países, de acordo com suas especificidades, precisam adequar a distribuição das receitas de royalties, ampliando o rol de beneficiados e incluindo critérios de recebimento para outros que não tiveram a sorte de ter recursos minerais e petrolíferos em seu território. Naturalmente, essa é uma conclusão simplificada, que está ignorando todos os outros fatores possíveis, para focar na finalidade dos royalties, pois se eles servem para compensar o poder público pela exploração de um recurso seu, e se esse recurso pertence à sociedade, seria adequado ampliar as instâncias da sociedade que são beneficiadas.

O último eixo de análise eleito é o que concerne ao uso adequado das receitas. Esse uso adequado seria aquele que observasse questões de intergeracionalidade, privilegiando gastos que teriam efeitos benéficos também no futuro, ou investimentos cujos valores e efeitos positivos se prolongariam ao longo do tempo. Nesse eixo, embora o Brasil leve vantagem sobre os Estados Unidos, a partir dos instrumentos desenhados, na prática, o que se nota é um esvaziamento das tentativas de gestão fiscal intergeracional. 
Ao menos no que tange aos aspectos formais, o ordenamento jurídico brasileiro apresenta diversas limitações ao uso das receitas de royalties, sendo vedada a sua aplicação para pagamento de dívida e gastos com o quadro permanente de pessoal, visando, assim, a impedir que esses recursos sejam usados para finalidades que não necessariamente trariam benefícios perenes, isto é, que não fossem considerados como investimento desses valores. Não obstante, outros dispositivos legislativos já permitiram o uso para finalidades não necessariamente adequadas, que se elegeram neste trabalho como essenciais (tais como fundos de previdência).

O próprio mecanismo do Fundo Social, criado nas mudanças do marco regulatório do petróleo, não sobreviveu às tentativas de esvaziar os mecanismos de gestão fiscal e garantir aos governantes o uso amplo e irrestrito das receitas. Esse fundo teria sido criado para fins de poupança e com regras rígidas de gastos e aplicação, mas nunca foi efetivamente regulamentado, tendo seus recursos esvaziados posteriormente, para aplicação em saúde pública e educação básica. Entende-se que esses gastos são essenciais e possuem sim características intergeracionais. Não obstante, chama-se atenção para o total desprezo de regras de limitação de uso de recursos, que não seja o gasto imediato.

Nos Estados Unidos, ao contrário do Brasil, não foi possível encontrar regras amplas de limitações de gastos com essas receitas, havendo, ao contrário, a possibilidade de uso amplo e irrestrito. Uma das poucas limitações encontrada se refere à exploração de petróleo offshore no Golfo do México, cuja legislação determina que os valores recebidos pelos Estados costeiros da região observem finalidades específicas, tais como questões de conservação, projetos de infraestrutura etc. De resto, porém, presume-se que a liberdade de gasto é ampla.

A adoção de mecanismos de fundos nos Estados Unidos também é distinta, pois não se voltam para questões intergeracionais, tal como costumeiramente pensadas (e.g. gastos em questões de infraestrutura). No nível federal, foram localizados três fundos que recebem receitas de royalties, um voltado para projetos de irrigação em regiões áridas no Oeste, outro direcionado à preservação de parques e florestas nacionais, e um terceiro cuidando de sítios históricos. Apesar de conter características intergeracionais implícitas em algumas dessas finalidades, elas não tornariam necessariamente as receitas perenes. De 
todo modo, ao menos para um fundo foram localizados dados de apropriação dos valores depositados e uso em outras questões.

Em nível estadual existe o fundo mais famoso, o Alaskan Permanent Fund, cuja criação se deu para preservar os valores arrecadados e investi-los em ativos voltados para questões produtivas, o que visa a garantir a perenidade dos recursos, sendo proibido o gasto do principal, podendo ser usados apenas os lucros. Na prática, os lucros do fundo são apropriados pelos governantes, que redistribuem todos os valores aos cidadãos, por meio de cheques. Naturalmente, esse gasto, embora útil, na visão dos cidadãos, não é adequado para a finalidade intergeracional que ora se discute, até pelo fato que esse Estado abriu mão de cobrar outras receitas, tal como imposto de renda dos seus residentes. ${ }^{492}$

Percebe-se, portanto, que ambos os países são deficientes no que tange ao uso dos royalties, o que permite o esvaziamento dessas receitas, cuja arrecadação tende a diminuir ao longo do tempo, dada a esgotabilidade da sua fonte de origem.

Antes de analisar se algum ordenamento jurídico trata a gestão dos seus recursos naturais e das receitas deles oriundas de forma adequada, propuseram-se alguns eixos de análise que podem ou não coincidir com as finalidades para os quais foram criados em seu país natal. A partir da análise dos eixos propostos, é possível apresentar conclusões sobre a atuação estatal e o seu desenho.

Iniciou-se esta conclusão com a constatação que o Brasil não seria retrógado em comparação as Estados Unidos, observação que se mantém, pois, apesar das várias deficiências legislativas que existem, há pelo menos um esqueleto de normas que visa a aprimorar os regimes de exploração, arrecadação, distribuição e uso dos royalties. Isso nem sempre existe nos Estados. Muitas mudanças precisam ser instituídas, principalmente nos processos de aplicação das normas, para que o Brasil alcance um regime jurídico funcional e eficiente da gestão dos seus recursos naturais. De todo modo, o país tem ao menos uma noção do caminho que precisa ser trilhado.

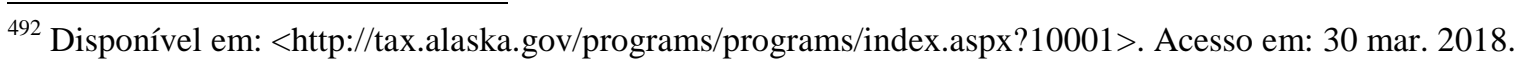




\section{REFERÊNCIAS}

AFONSO, José Roberto Rodrigues; GOBEETTI, Sérgio Wulff. Rendas do petróleo no Brasil: alguns aspectos fiscais e federativos. Revista do BNDES, Rio de Janeiro, v. 15, n. 30, p. 231-269, dez. 2008. Disponível em:

<https://web.bndes.gov.br/bib/jspui/handle/1408/10115>. Acesso em: 25 abr. 2018.

ALMEIDA, Aloísio Flávio Ferreira de; ALMEIDA, Carlos Otávio Ferreira de. O equilíbrio federativo como desafio ao novo formato do Fundo de Participação dos Estados (FPE). Revista Fórum de Direito Financeiro e Econômico: RFDFE, Belo Horizonte, v. 2, n. 2, p. 13-34, set. 2012/fev. 2013.

ALMEIDA, Fernando Menezes de. A legislação federal sobre ciência, tecnologia e inovação no contexto da organização federativa brasileira. In: FREITAS, Rafael Verás de; RIBEIRO, Leonardo Coelho; FEIGELSON, Bruno (Coords.). Regulação e novas tecnologias. Belo Horizonte: Fórum, 2017. p. 99-110.

ALMEIDA FILHO, Agassiz; BARROS, Vinícius Soares de Campos. Novo manual da ciência política. 2 ed. São Paulo: Malheiros, 2013.

ALVES, Victor Rafael Fernandes. Royalties petrolíferos: regulação e sustentabilidade. Rio de Janeiro: Lumen Juris, 2017.

ANGRISANI, Vera. Plano de recuperação das áreas degradadas (PRAD) pela atividade minerária. In: YOSHIDA, Consuelo Yatsuda Moromizato; REMÉDIO JÚNIOR, José Ângelo (Orgs.). Direito minerário e direito ambiental: fundamentos e tendências. Rio de Janeiro: Lumen Juris, 2014. p. 431-460.

ANTUNES, Paulo de Bessa. Para que serve a CFEM? Valor Econômico, Legislação, São Paulo, Edição de 01 dez. 2015.

ARAUJO, Luiz Alberto David. O federalismo brasileiro. In: CLÈVE, Clèmerson Merlin; BARROSO, Luís Roberto (Orgs.). Organização do Estado: federalismo. São Paulo:

Revista dos Tribunais, 2011. Cap. 1, p. 137-150. (Doutrinas Essenciais. Direito

Constitucional, v. 3).

ARAUJO, Cíntia Rejane Möller de; ARAUJO, Luiz Alberto David. Intervenção: as crises econômicas atuais, os cortes de orçamento, os grupos vulneráveis e o exercício democrático. In: POMPEU, Gina; CARDUCCI, Michelle; ARAUJO, Luiz Alberto David (Orgs.). A constituição à prova da crise financeira internacional. Florianópolis: Empório do Direito, 2017. p. 347-354.

ARBIX, Glauco. À espera da mão invisível. Outra vez? Novos Estudos Cebrap, São Paulo, edição especial, p. 29-40, jun. 2017. Disponível em: <http://novosestudos.uol.com.br/wpcontent/uploads/2017/06/\%C3\%80-ESPERA-DA-M\%C3\%83O-INVIS\%C3\%8DVEL.OUTRA-VEZ-Glauco-Arbix.pdf>. Acesso em: 10 mar. 2018. 
ARBIX, Glauco; MARTIN, Scott. Beyond developmentalism and market fundamentalism in Brazil: inclusionary state activism without statism. March 12-13, 2010. Disponível em: <http://www.law.wisc.edu/gls/documents/paper_arbix.pdf>. Acesso em: 08 maio 2018.

ASSUNÇÃO, Matheus Carneiro. Novos critérios de rateio do Fundo de Participação dos Estados e do Distrito Federal: inconstitucionalidade persistente? Revista Fórum de Direito Financeiro e Econômico: RFDFE, Belo Horizonte, v. 3, n. 5, p. 109-115, mar./ago. 2014.

ATHIAS, Daniel Tobias. Institutional by-pass: o exemplo do Regime Diferenciado de Contratações (RDC). Revista Fórum de Direito Financeiro e Econômico: RFDFE, Belo Horizonte, v. 3, n. 3, p. 253-268, mar./ago. 2013.

ATHIAS, Jorge Alex Nunes. A ordem econômica e a Constituição de 1988. Belém: Cejup, 1997.

BACKMAN, Kimberly A. North Dakota. In: STRONG, Christopher B. (Ed.). The oil \& gas law review. $4^{\text {th }}$ ed. London: Law Business Research, 2016. Cap. 20, p. 219-229.

BAKKEN, Gordon Morris. The mining law of 1872: past, politics and prospects. Albuquerque: University of New Mexico Press, 2008.

BALERONI, Rafael Baptista; PEDROSO JÚNIOR, Jorge Antônio. Pré-Sal: desafios e uma proposta de regulação. In: RIBEIRO, Marilda Rosado de Sá (Org.). Novos rumos do direito do petróleo. Rio de Janeiro: Renovar, 2009. p. 149-207.

BARACHO, José Alfredo de Oliveira. A federação e a revisão constitucional. In: CLÈVE, Clèmerson Merlin; BARROSO, Luís Roberto (Orgs.). Organização do Estado: federalismo. São Paulo: Revista dos Tribunais, 2011. Cap. 1, p. 121-136. (Doutrinas Essenciais. Direito Constitucional, v. 3).

BARBOSA, Alfredo Ruy. Breve panorama da legislação minerária. Revista de Direito Administrativo, Rio de Janeiro, v. 197, p. 64-73, jul. 1994.

BARBOSA, Alfredo Ruy. A natureza jurídica da concessão para exploração de petróleo e gás natural. In: PIRES, Paulo Valois (Org.). Temas do direito do petróleo e do gás natural II. Rio de Janeiro: Lumen Juris, 2005. p. 1-28.

BARROS, Octavio de; PEREIRA, Robson Rodrigues. Desmistificando a tese da desindustrialização: reestruturação da indústria brasileira em uma época de transformações globais. In: BARROS, Octavio de; GIAMBIAGI, Fabio. (Orgs.). Brasil globalizado: o Brasil em um mundo surpreendente. 3. ed. Rio de Janeiro: Elsevier; Campus, 2008. p. 299330.

BARROSO, Rafael Mendes Cunha. Federalismo fiscal no Brasil: o impacto das transferências orçamentárias na desconcentração de receitas entre as esferas de governo. Revista Controle: doutrinas e artigos, Fortaleza, v. 11, n. 1, p. 79-104, jan. 2013. Disponível em: <http://revistacontrole.ipc.tce.ce.gov.br/index.php/RCDA/article/view/258/260>. Acesso em: 08 abr. 2018. 
BASTOS, Celso Ribeiro; MARTINS, Ives Gandra da Silva. Comentários à Constituição do Brasil: promulgada em 5 de outubro de 1988: arts. 18 a 23. 2. ed. atual. São Paulo: Saraiva, 2001. v. 3, t. 1.

BASTOS, Pedro Paulo Zahluth. A construção do nacional-desenvolvimentismo de Getúlio Vargas e a dinâmica de interação entre Estado e mercado nos setores de base. Revista Economia, Brasília, v. 7, n. 4, 239-275, dez. 2006.

BERCOVICI, Gilberto. Constituição econômica e desenvolvimento: uma leitura a partir da constituição de 1988. São Paulo: Malheiros, 2005.

BERCOVICI, Gilberto. Desigualdades regionais, Estado e Constituição. São Paulo: Max Limonad, 2003.

BERCOVICI, Gilberto. Direito econômico do petróleo e dos recursos minerais. São Paulo: Quartier Latin, 2011.

BERCOVICI, Gilberto. Política econômica e direito econômico. Revista Fórum de Direito Financeiro e Econômico: RFDFE, Belo Horizonte, v. 1, n. 1, p. 199-219, mar./ago. 2012.

BERCOVICI, Gilberto. Petrobras: monopólio estatal e política concorrencial. Revista Fórum de Direito Financeiro e Econômico: RFDFE, Belo Horizonte, v. 3, n. 5, p. 135-148, mar./ago. 2014.

BERCOVICI, Gilberto; MASSONETTO, Luís Fernando. A constituição dirigente invertida: a blindagem da constituição financeira e a agonia da constituição econômica. Boletim de Ciências Económicas, Coimbra, Faculdade de Direito da Universidade de Coimbra, v. 49, p. 57-77, 2006. Disponível em: <https://digitalisdsp.uc.pt/jspui/bitstream/10316.2/24845/3/BoletimXLIX_Artigo2.preview.pdf >. Acesso em: 09 maio 2018.

BERNARDES, Flávio Couto; HEIDENREICH, Freitrich. A suspensão dos efeitos do novo marco regulatório dos royalties do petróleo: ofensa ao federalismo fiscal brasileiro? Revista da Procuradoria Geral do Município de Belo Horizonte: RPGMBH. v. 6, n. 12, p. 15-33, jul./dez. 2014.

BEVILACQUA, Lucas. Fundos constitucionais de financiamento sob a perspectiva de uma nova política de desenvolvimento regional para o Brasil Central. Revista Fórum de Direito Financeiro e Econômico: RFDFE, Belo Horizonte, v. 5, n. 8, p. 99-117, set./fev. $2015 / 2016$.

BIM, Eduardo Fortunato. Licenciamento ambiental. 2. ed. Rio de Janeiro: Lumen Juris, 2015.

BITAR, Orlando. Obras completas de Orlando Bitar. Brasília: Conselho Federal de Cultura, 1978. v. 3.

BLOCK, Fred; EVANS, Peter. The state and the economy. In: SMELSER, Neil; SWEDBERG, Richard (Eds.) The handbook of economic sociology. $2^{\text {nd }}$ ed. Princeton, NJ: Princeton University Press 2005. p. 505-526. 
BORJA, Célio. Federalismo brasileiro. Revista de Direito Público, São Paulo, v. 18, n. 73, p. 138-144, jan./mar. 1985.

BORNHOLDT, Rodrigo Meyer. Royalties do petróleo e as questões constitucionais. Interesse Público, Belo Horizonte, Fórum, v. 12, n. 62, p. 125-134, jul./ago. 2010.

BRESSER-PEREIRA, Luiz Carlos. Desenvolvimento e crise no Brasil: história, econômica e política de Getúlio Vargas a Lula. 5. ed. atual. São Paulo: Editora 34, 2003.

BRESSER-PEREIRA, Luiz Carlos (Org.). Doença holandesa e indústria. Rio de Janeiro: Editora FGV, 2010.

BUSTAMANTE, Luiz Alberto da Cunha; CAVALCANTE FILHO, João Trindade; BIATO, Márcia Fortuna; GOMES, Carlos Jacques Vieira. Análise do Projeto de Lei de Marco Regulatório da Mineração do Brasil. Brasília: Núcleo de Estudos e Pesquisas/CONLEG/Senado, set./2013 (Texto para Discussão no 137). Disponível em: $<$ https://www12.senado.leg.br/publicacoes/estudos-legislativos/tipos-de-estudos/textospara-discussao/td-137-analise-do-projeto-de-lei-de-marco-regulatorio-da-mineracao-dobrasil>. Acesso em: 08 abr. 2018.

CALABRESI, Guido; BOBBIT, Philip. Tragic Choices: The conflicts society confronts in the allocation of tragically scarce resources. New York: Norton, 1978.

CALASANS JUNIOR, José. Autorização de pesquisa mineral - Direito de prioridade Transferência. Revista de Direito Administrativo, Rio de Janeiro, v. 209, p. 356-361, jul. 1997.

CANOTILHO, José Joaquim Gomes; MENDES, Gilmar Ferreira; SARLET, Ingo Wolfgang; STRECK, Lenio Luiz (Coords.). Comentários à Constituição do Brasil. São Paulo: Saraiva; Almedina, 2013.

CARREIRA, Liberato de Castro. História financeira e orçamentária do Império do Brasil: após a guerra do Paraguai. Brasília: Senado Federal, Centro Gráfico; Rio de Janeiro: Fundação Casa de Rui Barbosa, 1980. v. 2.

CARVALHO, André Castro. Direito da infraestrutura: perspectiva pública. São Paulo: Quartier Latin, 2014.

CARVALHO, André Castro. Vinculação de receitas públicas. São Paulo: Quartier Latin, 2010.

CASTRO, Antonio Falabella de. O manifesto de mina em face da compensação financeira (Lei n. 7.990/89). In: SOUZA, Marcelo Mendo Gomes de (Coord.). Direito minerário aplicado. Belo Horizonte: Mandamentos, 2003. p. 221-262.

CASTRO JÚNIOR, Paulo Honório de; SILVA Tiago de Mattos. CFEM e manifesto de mina: um estudo de caso. In: AZEVEDO, Marcelo et al. Direito da mineração: questões minerárias, ambientais e tributárias. Belo Horizonte: D’Plácido, 2017. Cap. 26, p. 617-648. 
CAVALCANTI, Amaro. Regime federativo e república brasileira. Brasília: Universidade de Brasília, 1983.

CAVALCANTI, Temístocles Brandão. A ordem econômica nas constituições. Revista Forense, Rio de Janeiro, v. 46, n. 122, p. 339-345, mar./abr. 1949.

CHANG, Ha-Joon. Chutando a escada: a estratégia do desenvolvimento em perspectiva histórica. Tradução de Luiz Antônio Oliveira de Araújo. São Paulo: Unesp, 2004.

CHANG, Ha-Joon. Hamlet without the Prince of Denmark: how development has disappeared from today's 'development' discourse. In: KHAN, Shahrukh Rafi; CHRISTIANSEN, Jens (Eds.). Towards new developmentalism: market as means rather than master. London; New York: Routledge, 2013. p. 129-148.

CHURCHILL, Winston. A sutileza bem-humorada de Winston Churchill: suas grandes tiradas... Organizado por Richard Langworth; tradução de Joubert de Oliveira Brízida. Rio de Janeiro: Odisseia, 2012.

CLÈVE, Clèmerson Merlin; KENICKE, Pedro Henrique Gallotti. Federalismo, centralização e princípio da simetria. In: LEITE, George Salomão et al. (Coords.). Ontem, os códigos! Hoje, as constituições: homenagem a Paulo Bonavides. São Paulo: Malheiros, 2016. Parte 2, cap. 5, p. 76-90.

CLÈVE, Clèmerson Merlin; MARTINS, Alessandra Ferreira. Princípios constitucionais da atividade econômica petrolífera e Lei no 9.478 de 1997. A\&C: Revista de Direito Administrativo e Constitucional, Belo Horizonte, v. 4, n. 18, p. 43-50, out./dez. 2004.

COHEN, Stephen S.; DELONG, J. Bradford. Concrete economics: the Hamilton approach to economic growth and policy. Boston: Harvard Business Review Press, 2016.

COMPARATO, Fabio Konder. Educação, Estado e poder. São Paulo: Brasiliense, 1987.

COMPARATO, Fábio Konder. O indispensável direito econômico. Revista dos Tribunais, São Paulo, v. 54, n. 353, p. 14-26, mar. 1965.

COMPARATO, Fábio Konder. A oligarquia brasileira: visão história. São Paulo: Contracorrente, 2017.

CONTI, José Maurício. Considerações sobre o federalismo fiscal brasileiro em uma perspectiva comparada. In: CONTI, José Maurício; SCAFF, Fernando Facury; BRAGA, Carlos Eduardo Faraco (Coords.). Federalismo fiscal: questões contemporâneas. Florianópolis: Conceito Editorial, 2010. p. 15-34.

CONTI, José Maurício. Federalismo fiscal e fundos de participação. São Paulo: Juarez de Oliveira, 2001.

COOTER, Robert; ULEN, Thomas. Direito e economia. 5. ed. Porto Alegre: Bookman, 2010. 
COSTA, Regina Helena. A natureza jurídica da compensação financeira pela exploração de recursos minerais. Revista da Procuradoria Geral do Estado de São Paulo, n. 47/48, p. 125-133, jan./dez. 1997.

COSTIGAN, George P. Handbook on american mining law. St. Paul: West Publishing Co., 1908.

COUTINHO, Diogo R.; SCHAPIRO, Mario G. Economia política e direito econômico: do desenvolvimentismo aos desafios da retomada do ativismo estatal. In: COSTA, José Augusto Fontoura; ANDRADE, José Maria Arruda de; MATSUO, Alexandra Mery Hansen (Orgs.). Direito: teoria e experiência: estudos em homenagem a Eros Roberto Grau. São Paulo: Malheiros, 2013. p. 581-617.

DAHL, Robert Alan. A Constituição norte-americana é democrática? Tradução de Vera Ribeiro. Rio de Janeiro: FGV Editora, 2015.

DAINTITH, Terence. Finders keepers?: how the law of capture shaped the world oil industry. Washington, DC: RFF Press, 2010.

DANTAS, Marcelo Buzaglo. Direito ambiental de conflitos. Rio de Janeiro: Lumen Juris, 2015.

DAVID, René. Os grandes sistemas do direito contemporâneo. Tradução de Hermínio A. Carvalho. 5. ed. São Paulo: Martins Fontes, 2014.

DIAMOND, Jared M. Colapso: como as sociedades escolhem os fracassos ou o sucesso. 5. ed. Tradução de Alexandre Raposo. São Paulo: Record, 2007.

DIEGUEZ, Consuelo. O estouro da boiada. Revista Piauí, n. 101, fev. 2015. Disponível em: <http://piaui.folha.uol.com.br/materia/o-estouro-da-boiada/>. Acesso em: 10 mar. 2018 .

DIEGUEZ, Consuelo. O setembro negro da Sadia. Revista Piauí, n. 38, nov. 2009 Disponível em: <http://piaui.folha.uol.com.br/materia/o-setembro-negro-da-sadia/>. Acesso em: 10 mar. 2018.

DOMINGUES, José Marcos. Cobrança pelo uso da água: natureza jurídica: as cobranças estaduais. Interesse Público: revista bimestral de direito público, Belo Horizonte, v. 8, n. 39, p. 299-319, set./out. 2006.

DOMINGUES, José Marcos; CARNEIRO, Júlia Silva Araújo. A compensação ambiental prevista pelo Sistema Nacional de Unidades de Conservação (SNUC): a ADI no 3.378 e o Decreto no 6.848/09. Revista Direito GV [online], v. 6, n. 2, p. 493-502, jul./dez. 2010. Disponível em: <http://www.scielo.br/pdf/rdgv/v6n2/a07v6n2.pdf>. Acesso em: 20 mar. 2018.

DÓRIA, Antônio Roberto Sampaio. Discriminação de rendas tributárias. São Paulo, José Bushatsky, 1972.

DWORKIN, Ronald. John Rawls. The Harvard Review of Philosophy, v. 11, p. 7-8, 2003. 
ENRIQUEZ, Maria Amélia. Mineração: maldição ou dádiva?: os dilemas do desenvolvimento sustentável a partir de uma base mineira. São Paulo: Signus, 2008.

FARIAS, Talden; ATAIIDE, Pedro. Mudar legislação minerária por meio de medida provisória é decisão equivocada. Consultor Jurídico, São Paulo, 04 ago. 2017. Disponível em: <https://www.conjur.com.br/2017-ago-04/opiniao-mudar-codigo-minerario-meio-mpdecisao-equivocada>. Acesso em: 18 nov. 2017.

FERNANDES, Andressa Guimarães Torquato. Uma análise acerca da classificação das receitas petrolíferas na lei orçamentária. In: CONTI, José Maurício; SCAFF, Fernando Facury (Coords.). Orçamentos públicos e direito financeiro. São Paulo: Revista dos Tribunais, 2011. p. 433-451.

FERNANDES, Andressa Guimarães Torquato. Royalties do petróleo e orçamento público: uma nova teoria. São Paulo: Blucher, 2016.

FERRAZ, Roberto. Instrumentos econômicos de proteção ao meio ambiente: o art. 36 da Lei 9.985/00. In: SCAFF, Fernando Facury; ATHIAS, Jorge Alex (Coords.). Direito tributário e econômico aplicado ao meio ambiente e à mineração. São Paulo: Quartier Latin, 2009. p. 328-349.

FERREIRA FILHO, Manoel Gonçalves. Comentários à Constituição brasileira de 1988: arts. $1^{\circ}$ a 43. São Paulo: Saraiva, 1990. v. 1.

FERREIRA FILHO, Manoel Gonçalves. Comentários à Constituição brasileira de 1988: arts. $1^{\circ}$ a 103. 3. ed. atual. São Paulo: Saraiva, 2000. v. 1.

FIGUEIREDO, Yuri Jordy Nascimento. Licenciamento ambiental: instrumento de desenvolvimento regional ou defesa do meio físico?: um estudo sobre condicionantes socioambientais. 2017. 217 p. Tese (Doutorado) - Faculdade de Direito da Universidade de São Paulo, 2017.

FIGUEIREDO, Yuri Jordy Nascimento. Licenciamento ambiental da mineração: avanços, perspectivas e novos desafios para a efetividade da norma-princípio do "desenvolvimento sustentável". Revista de Direito Ambiental, São Paulo, v. 18, n. 72, p. 451-474, out./dez. 2013.

FOX, William F. The United States of America: the practice of fiscal federalism: comparative perspectives. London: McGill-Queen's University Press, 2006. (A Global Dialogue on Federalism, v. 4).

FRANCO, António Luciano de Sousa. Finanças públicas e direito financeiro. 4. ed. Coimbra: Almedina, 2007. v. 2.

FREIRE, William. Natureza jurídica do consentimento para pesquisa mineral, do consentimento para lavra e do manifesto de mina no direito brasileiro. Belo Horizonte: Mineira Livros Jurídicos, 2005.

FRIEDMAN, Lawrence M. A history of american law. 2nd ed. New York: Simon \& Schuster, 1985. 
FRIEDMAN, Lawrence M. The law and society movement. Stanford Law Review, v. 38, No. 38, p. 763-780, Feb. 1986.

FULLERTON, Don. Why have separate environmental taxes? Tax Policy and the Economy, Chicago, IL, University of Chicago Press, v. 10, p. 33-70, 1996. Disponível em: <https://www.journals.uchicago.edu/doi/pdfplus/10.1086/tpe.10.20061836>. Acesso em: 10 abr. 2018.

FURTADO, Celso. Desenvolvimento e subdesenvolvimento. Rio de Janeiro: Contraponto; Centro Internacional Celso Furtado, 2009.

FURTADO, Celso. Ensaios sobre a Venezuela: subdesenvolvimento com abundância de divisas. Rio de Janeiro: Contraponto; Centro Internacional Celso Furtado, 2008.

FURTADO, Celso. A invenção do subdesenvolvimento. Revista de Economia Política, São Paulo, v. 15, n. 2, (58), p. 5-9, abr./jun. 1995. Disponível em: <http://www.rep.org.br/PDF/58-1.PDF>. Acesso em: 10 abr. 2018.

FURTADO, Celso. Prefácio. In: NUNES, António José Avelãs. Industrialização e desenvolvimento: a economia política do 'modelo brasileiro de desenvolvimento'. São Paulo: Quartier Latin, 2005. p. 25-27.

GATES, Paul W. An overview of American land policy. Agricultural History, v. 50, No. 1, p. 213-229, jan. 1976. Disponível em: <http://www.jstor.org/stable/3741919>. Acesso em: 10 abr. 2018.

GONÇALVES, Andrea Viggiano. A participação do proprietário do solo nos resultados da lavra de mina manifestada. In: SOUZA, Marcelo Mendo Gomes de (Coord.). Direito minerário em evolução. Belo Horizonte: Mandamentos, 2009. p. 277-292.

GOODRICH, Carter. Government promotion of american canals and railroads (18001890). Westport, Conn.: Greenwood Press, 1974.

GOODRICH, Carter. Local government planning of internal improvements. Political Science Quarterly, v. 66, No. 3, p. 411-445, Sept. 1951.

GOODRICH, Carter. National planning of internal improvements. Political Science Quarterly, v. 63, No. 1, p. 16-44, Mar. 1948.

GRAU, Eros Roberto. Comentário aos artigos 176 e 177. In: CANOTILHO, José Joaquim Gomes; MENDES, Gilmar Ferreira; SARLET, Ingo Wolfgang; STRECK, Lenio Luiz (Coords.). Comentários à Constituição do Brasil. São Paulo: Saraiva; Almedina, 2013. p. 1.843-1.852.

GRODZINS, Morton. The American system: a new view of government in the United States. Edited by Daniel J. Elazar. Chicago: Rand McNally, 1966.

GUIMARÃES, Bernardo Strobel; OLBERTZ, Karlin. Federação e royalties. In: ARAGÃO, Alexandre Santos de (Coord.). Direito do petróleo e de outras fontes de energia. Rio de Janeiro: Lumen Juris, 2011. p. 41-58. 
HABER, Stephen H.; MENALDO, Victor A. Do natural resources fuel authoritarianism?: a reappraisal of the resource curse. American Political Science Review, v. 105, No. 1, p. 126, Feb. 2011.

HAMILTON, Alexander; MADISON, James; JAY, John. O federalista. Tradução, introdução e notas de Viriato Soromenho-Marques, João C. S. Duarte. 2. ed. Lisboa: Fundação Calouste Gulbenkian, 2011.

HARADA, Kiyoshi. Direito financeiro e tributário. 18. ed. São Paulo: Atlas, 2009.

HEIN, Jayni Foley; CECOT, Caroline. Mineral royalties: historical uses and justifications. Duke Environmental Law \& Policy Forum, v. 28, No. 1, 2017. Disponível em:

<https://papers.ssrn.com/sol3/papers.cfm?abstract_id=2918357>. Acesso em: 12 out. 2017.

HILLS, Roderick M. Federalism in constitutional context. Harvard Journal of Law \& Public Policy, v. 22, No. 1, p. 181-196, Fall 1998.

HOLSTON, James. Cidadania insurgente: disjunções da democracia e da modernidade no Brasil. Tradução de Cláudio Carina; revisão técnica de Luísa Valentini. São Paulo: Companhia das Letras, 2013.

INCE, Onur Ulas. Colonial capitalism and the dilemmas of liberalism. New York: Oxford University Press, 2018.

KARL, Terry Lynn. The paradox of plenty: oil booms and petro-states. Berkeley: University of California Press, 1997.

KHRAICHE, Maroula; FLAHERTY, Patrick. Federalismo fiscal: el caso de Estados Unidos. Traducción de Gema Fernández-Avilés Calderón. CLM. Economía: Revista Económica de Castilla-La Mancha, n. 8, p. 325-354, 2006. Disponível em:

<http://www.clmeconomia.jccm.es/pdfclm/maroula_8.pdf>. Acesso em: 10 abr. 2018.

KINCAID, John. United States of America. In: MORENO, Luis; COLINO, César; KINCAID, John. Diversity and unity in federal countries. London: McGill-Queen's University Press, 2005. (A Global Dialogue on Federalism v. 7).

KLARMAN, Mike. The Constitution as a coup against the public opinion. Revista de Estudos Institucionais, Rio de Janeiro, Universidade Federal do Rio de Janeiro, v. 3, n. 1, p. 255-266, jul. 2017. Disponível em:

<https://estudosinstitucionais.com/REI/article/view/147/135>. Acesso em: 10 abr. 2018.

KRELL, Andreas Joachim. Licença ou autorização ambiental?: muita discussão em torno de um falso dilema. Revista de Direito Ambiental, São Paulo, Revista dos Tribunais, v. 13, n. 49, p. 56-72, jan./mar. 2008.

LAITOS, Jan G.; TOMAIN, Joseph P. Energy and natural resources law in a nutshell. St. Paul, Minn.: West Publishing Co., 1992. 
LARSEN, Erling Røed. Escaping the resource curse and the dutch disease?: when and why Norway caught up with and forged ahead of its neighbors. Discussion Paper No. 377, May 2004. Statistics Norway, Research Department. Disponível em:

<https://www.ssb.no/a/publikasjoner/pdf/DP/dp377.pdf>. Acesso em: 20 mar. 2018.

LAZZARI, Salvatore. The federal royalty and tax treatment of the hardrock mineral industry: an economic analysis. Washington, District of Columbia: Congressional Research Service, 2008. (CRS Report for Congress, RL34268).

LECKRONE, J. Wesley. American federalism in practice: intergovernmental cooperative tension. In: RAMOS, Dircêo Torrecillas (Coord.). O federalista atual: teoria do federalismo. Belo Horizonte: Arraes Editores, 2013. p. 436-456.

LEITE, Camila Morais; MARCUCI, Roberta Borella. A CFEM como indenização ambiental. In: SILVA, Paulo Roberto Coimbra (Coord.). CFEM: compensação financeira pela exploração de recursos minerais: natureza jurídica e questões correlatas. São Paulo: Quartier Latin, 2010. p. 104-124.

LEITE, Fabricio do Rozario Valle Dantas. As participações governamentais na indústria do petróleo sob a perspectiva do estado-membro: importância econômica, natureza jurídica e possibilidade de fiscalização direta. Revista Direito $G V$ [online], v. 5, n. 2, p. 527-548, jul. 2009. Disponível em:

<http://bibliotecadigital.fgv.br/ojs/index.php/revdireitogv/article/view/24327>. Acesso em: 07 fev. 2018.

LEITE, Marcelo et al. A batalha de Belo Monte. Folha de S.Paulo, 16 dez. 2013. Disponível em: <http://arte.folha.uol.com.br/especiais/2013/12/16/belo-monte/>. Acesso em: 25 set. 2017.

LEONHARDT, Roberta Danelon. Limits on the principles of permanent sovereignty over natural resources: foreign investment and contractual guarantees. Revista de Direito Ambiental: RDA, São Paulo, v. 11, n. 44, p. 165-201, out./dez. 2006.

LEWANDOWSKI, Enrique Ricardo. Pressupostos materiais e formais da intervenção federal no Brasil. São Paulo: Revista dos Tribunais, 1994.

LEWIN, Tobias. The history of government property in minerals in the United States. Washington University Law Review, v. 16, No. 3, p. 245-252, Jan. 1931. Disponível em: $<$ https://openscholarship.wustl.edu/cgi/viewcontent.cgi?article $=4805 \&$ context=law_lawrev iew>. 10 abr. 2018.

LIMA, Hernani Mota de; FLORES, José Cruz do Carmo; COSTA, Flávio Luiz. Plano de recuperação de áreas degradadas versus plano de fechamento de mina: um estudo comparativo. Rem: Revista Escola de Minas, Ouro Preto, MG, v. 59, n. 4, p. 397-402, out./dez. 2006.

LIMA, Paulo César Ribeiro. Pré-sal: o novo marco legal e a capitalização da Petrobras. Rio de Janeiro: Synergia, 2011. 
LOBATO, Monteiro. O poço do visconde. São Paulo: Brasiliense, 1960.

LOUREIRO, Gustavo Kaercher. Participações governamentais na indústria do petróleo: evolução normativa. Porto Alegre: Sergio Antonio Fabris, 2012.

MACHADO, Frederico Munia. A evolução histórica da legislação sobre os royalties da mineração brasileira. In: SOUZA, Marcelo Mendo Gomes de (Coord.). A compensação financeira pela exploração dos recursos minerais - CFEM. Belo Horizonte: Del Rey, 2011.p. 5-70.

MACHADO, José Angelo. Federalismo e políticas sociais: conexões a partir da teoria da agência. Revista do Serviço Público, Brasília, v. 69, n. 1, p. 57-84, jan./mar. 2018.

MARSHALL, Alfred. Princípios de economia: tratado introdutório. Tradução de Rômulo Almeida e Ottolmy Strauch. São Paulo: Nova Cultura, 1996.

MARQUES, José Frederico. Jazidas - Ato administrativo - Minas - Registro de imóveis. In: MILARÉ, Édis; MACHADO, Paulo Affonso Leme (Orgs.). Direito ambiental: conservação e degradação do meio ambiental. São Paulo: Revista dos Tribunais, 2011. Cap. 4, p. 1.145-1.178. (Coleção Doutrinas Essenciais. Direito Ambiental, v. 2).

MARQUES, Mauro Luiz Campbell. (As)simetrias no federalismo brasileiro. In: LEITE, George Salomão et al. (Coords.). Ontem, os códigos! Hoje, as constituições!: homenagem a Paulo Bonavides. São Paulo: Malheiros, 2016. p. 61-75.

MENDES, Gilmar Ferreira. Tributação e finanças públicas na Constituição Federal de 1988. In: MENDES, Gilmar Ferreira; BRANCO, Paulo Gustavo Gonet. Curso de direito constitucional. 6. ed. rev. e atual. São Paulo: Saraiva, 2011. p. 1.451-1.487.

MCGRANE, Reginald C. Foreign bondholders and american state debts. New York: The Macmillan Company, 1935.

MEIRA, Silvio Augusto de Bastos. Federalismo e centralização. Revista de Ciência Política, Instituto de Direito Público e Ciência Política, v. 22, n. 3, p. 81-94, jul./set. 1979.

MELLO, João Manuel Cardoso de. O capitalismo tardio. 11. ed. Campinas: Editora Unesp, 2009.

MENDONÇA, Elvino de Carvalho; SOUZA, Luciano Inácio de; MENDONÇA, Rachel Pinheiro de Andrade (Orgs.). A interface entre regulação e concorrência na cadeia produtiva do petróleo: análises de julgados do CADE. Ribeirão Preto, SP: Migalhas, 2017.

METCALF, Gilbert E. Environmental taxation: what have we learned in this decade? In: VIARD, Alan D. (Ed.) Tax policy lessons from the 2000s. Washington DC: The AEI Press, 2009. p. 7-34.

MIESZKOWSKI, Peter; SOLIGO, Ronald. United States. In: ANDERSON, George (Ed.). Oil \& gas in federal systems. Don Mills, Ontario, Canada: Oxford University Press, 2012. p. $310-338$. 
MILLER, David W. The historical development of the oil and gas laws of the United States. California Law Review, v. 51, No. 3, p. 506-534, 1963. Disponível em: $<$ https://scholarship.law.berkeley.edu/cgi/viewcontent.cgi?article=3039\&context=californi alawreview>. Acesso em: 20 mar. 2018.

MONTEIRO, Maurílio de Abreu; TEIXEIRA, Sheila do Socorro Lima. Mineração industrial e a estabilidade de assentamentos rurais no Sudeste do Estado do Pará, Brasil. In: ENCONTRO DA ASSOCIAÇÃO NACIONAL DE PÓS-GRADUAÇÃO E PESQUISA EM AMBIENTE E SOCIEDADE (ANPPAS), 3., 2006, Brasília, DF. Disponível em: $<$ https://sigaa.ufpa.br/sigaa/verProducao?idProducao=2473\&key=039d3c90d75e7daf120d 91595c4dc549>. Acesso em: 12 mar. 2018.

MORAES, Reginaldo Carmello Corrêa de; SILVA Maitá de Paula e. O peso do Estado na pátria do mercado: os Estados Unidos como país em desenvolvimento. São Paulo: Unesp, 2013.

MYERS, Will S. A legislative history of revenue sharing. The Annals of the American Academy of Political and Social Science. v. 419, No. 1, p. 1-11, May 1975.

NEDEL, José. A teoria da justiça de John Rawls: um esboço. In: ALMEIDA FILHO, Agassiz; BARROS, Vinícius Soares de Campos (Orgs.). Novo manual da ciência política: autores modernos e contemporâneos. 2. ed. São Paulo: Malheiros, 2013. p. 548-581.

NOHARA, Irene Patrícia; CÂMARA, Jacintho Arruda. Tratado de direito administrativo: licitação e contratos administrativos. São Paulo: Revista dos Tribunais, 2014. (Tratado de Direito Administrativo, v. 6 - Coordenação de Maria Sylvia Zanella Di Pietro).

NUNES, Antônio José Avelãs. Industrialização e desenvolvimento: a economia política do 'modelo brasileiro de desenvolvimento'. São Paulo: Quartier Latin, 2005.

NUSDEO, Fabio. Da política econômica ao direito econômico. 1977. 197 p. Tese (Livre Docência) - Faculdade de Direito da Universidade de São Paulo, São Paulo, 1977.

OLIVEIRA, Regis Fernandes de. Curso de direito financeiro. 7. ed. rev., atual. e ampl. São Paulo: Revista dos Tribunais, 2015.

OSTROW, Ashira Pelman. Land law federalism. Emory Law Journal. v. 61, No. 6, p. 1.397-1.444, Sept. 2012. Disponível em:

<http://law.emory.edu/elj/_documents/volumes/61/6/articles/ostrow.pdf >. Acesso em: 20 mar. 2018.

OTTO, James. Mining royalties: a global study of their impact on investors, government, and civil society. Washington, DC: The World Bank, 2006.

PAES, José Eduardo Sabo; OLIVEIRA, Marcos Roberto de. Características do sistema tributário nos Estados Unidos da América: alguns tópicos relevantes. Revista de Direito Internacional Econômico e Tributário: RDIET, Brasília, v. 10, n. 2, p. 52-78, jul./dez. 2015. Disponível em: <https://portalrevistas.ucb.br/index.php/RDIET/article/viewFile/6643/4208>. Acesso em: 20 mar. 2018. 
PAULSEN, Michael Stokes; PAULSEN, Luke. The Constitution: an introduction. New York: Basic Books, 2015.

PELLEGRINO, Maurício. O direito de participação nos resultados da lavra e seu vínculo ao direito de propriedade do imóvel em que se encontra a jazida. In: FERRARA, Mariana et al. (Coords.). Estudos de direito minerário. Belo Horizonte, Fórum, 2012. v. 1, p. 109125.

PEREIRA, Denise de Castro; WILDHAGEN, Raquel Oliveira; ROSA, Josiane Cláudia Sales et al. Cenários socioambientais em municípios com mineração: uma experiência extensionista. Belo Horizonte: PUC-Minas, 2012. Disponível em:

<http://www1.pucminas.br/documentos/forext_09.pdf>. Acesso em: 12 mar. 2018.

PEREIRA FILHO, João. Mineração - Direito de prioridade - Transmissibilidade. Revista de Direito Administrativo, Rio de Janeiro, v. 196, p. 175-189, abr. 1994.

PRADO JÚNIOR, Caio. História econômica do Brasil. 52. reimpressão. São Paulo: Brasiliense, 2011.

RAMOS, Paulo Roberto Barbosa. Federalismo: condições de possibilidade e características essenciais. Revista de Informação Legislativa, Brasília, v. 49, n. 193, p. 21 30, jan./mar. 2012.

RAWLS, John. Some reasons for the maximin criterion. American Economic Review, v. 64, No. 2, p. 141-146, 1974. Papers and proceedings of the Eighty-sixth Annual Meeting of the American Economic Association (May 1974).

RAWLS, John. Uma teoria da justiça. Tradução de Almiro Pisetta e Lenita M. R. Esteves. São Paulo: Martins Fontes, 1997.

RAYMOND, Daniel. Thoughts on political economy. In two parts. Baltimore: Fielding Lucas Junior, 1820.

REID, Michael. Brazil: the troubled rise of a global power. New Haven: Yale University Press, 2014.

REIS, João Francisco Garcia; SOUZA, Jaime Luiz Cunha de. Grandes projetos na Amazônia: a hidrelétrica de Belo Monte e seus efeitos na segurança pública. Dilemas: revista de estudos de conflito e controle social, Rio de Janeiro, v. 9, n. 2, p. 215-230, maio/ago. 2016. Disponível em:

<https://revistas.ufrj.br/index.php/dilemas/article/view/7730/6383>. Acesso em: 15 mar. 2018.

REZENDE, Fernando. Federal Republic of Brazil. In: SHAW, Anwar (Ed.). The practice of fiscal federalism: comparative perspectives. Montréal; London: Forum of Federations; McGill-Queen's University Press, 2007. p. 73-97. (A Global Dialogue on Federalism, v. 4).

RIBEIRO, Carlos Luiz. Direito minerário: escrito e aplicado. Belo Horizonte: Del Rey, 2006. 
RICARDO, David. Princípios de economia política e tributação. Tradução de Paulo Henrique Ribeiro Sandroni. São Paulo: Nova Cultura, 1996.

RIPERT, George. Aspectos jurídicos do capitalismo moderno. Tradução de Gilda G. de Azevedo. São Paulo: Freitas Bastos, 1947.

RIVERA, Tony Marcelo Gonzalez; MOREIRA, Rodrigo Leite. A incidência da CFEM sobre as minas manifestadas. In: TORRES, Heleno Taveira; CATÃO, Marcos André Vinhas (Coords.). Tributação no setor de petróleo. São Paulo: Quartier Latin, 2005. p. 373-382.

ROBERTS, Paul. This is what really happens when Amazon comes to your town: trust me, I saw my city transform - and not always for the better. 19 Oct. 2017. Politico Magazine. Disponível em: <http://www.politico.com/magazine/story/2017/10/19/amazonheadquarters-seattle-215725>. Acesso em: 19 mar. 2018.

ROCHA, Cármen Lúcia Antunes. República e federação no Brasil: traços constitucionais da organização política brasileira. Belo Horizonte: Del Rey, 1997.

RODRIGUES, C. H. L. A questão do protecionismo no debate entre Roberto Simonsen e Eugenio Gudin. 2005. 160 f. Dissertação (Mestrado) - Programa de Pós-Graduação em Ciências Econômicas, Instituto de Economia, Universidade Estadual de Campinas, Campinas, Campinas, SP, 2005.

ROESLER, Shannon M. Federalism and local environmental regulation. University of California Davis Law Review, v. 48, No. 3, p. 1.111-1.172, 2015. Disponível em:

<https://lawreview.law.ucdavis.edu/issues/48/3/Articles/48-3_Roesler.pdf>. 15 mar. 2018.

ROSS, Michael L. Does oil hinder democracy? World Politics, v. 53, No. 3, p. 325-361, Apr. 2001. Disponível em:

<https://scholar.harvard.edu/files/levitsky/files/ross_world_politics.pdf>. Acesso em: 25 abr. 2018.

ROSS, Michael L. The oil curse: how petroleum wealth shapes the development of nations. Princeton: Princeton University Press, 2012.

RUBINSTEIN, Flávio. Receitas públicas de recursos naturais no direito financeiro brasileiro. 2012. 317 p. Tese (Doutorado) - Faculdade de Direito da Universidade de São Paulo, 2012.

SAMPAIO, Patrícia Regina Pinheiro. Regulação da atividade de petróleo e do gás natural no Brasil. In: GUERRA, Sérgio (Org.). Regulação no Brasil: uma visão multidisciplinar. Rio de Janeiro: Editora FGV, 2014. p. 285-306.

SBRAGIA, Alberta M. Debt wish: entrepreneurial cities, U.S. federalism and economic development. Pittsburgh, PA: University of Pittsburgh Press, 1996. 
SCAFF, Fernando Facury. Anotações financeiras sobre os projetos do novo marco regulatório da mineração. In: YOSHIDA, Consuelo Yatsuda Moromizato; REMÉDIO JÚNIOR, José Ângelo. (Orgs.). Direito minerário e direito ambiental: fundamentos e tendências. Rio de Janeiro: Lumen Juris, 2014. p. 91-110.

SCAFF, Fernando Facury. Federalismo fiscal cooperativo no Brasil. In: LEITE, George Salomão et al. (Coord.). Ontem, os códigos! Hoje, as constituições!: homenagem a Paulo Bonavides. São Paulo: Malheiros, 2016. Parte 2, cap. 7, p. 106-122.

SCAFF, Fernando Facury. Federalismo fiscal patrimonial e fundo de equalização. O rateio dos royalties do petróleo no Brasil. In: HORVATH, Estevão; CONTI, José Maurício; SCAFF, Fernando Facury (Orgs.). Direito financeiro, econômico e tributário: homenagem a Regis Fernandes de Oliveira. São Paulo: Quartier Latin, 2014. p. 179-206.

SCAFF, Fernando Facury. A mens legislatoris constituinte no STF: entre royalties e ICMS. In: ROSA, Alexandre Morais da et al. (Orgs.). Hermenêutica, constituição, decisão judicial: estudos em homenagem ao professor Lenio Luiz Streck. Porto Alegre: Livraria do Advogado, 2016. p. 106-117.

SCAFF, Fernando Facury. MP de revitalização da indústria mineral é apenas aumento da CFEM. Consultor Jurídico [online], São Paulo, 08 ago. 2017. Disponível em: $<$ https://www.conjur.com.br/2017-ago-08/contas-vista-mp-revitalizacao-industria-mineralapenas-aumento-cfem>. Acesso em: 18 nov. 2017.

SCAFF, Fernando Facury. Notas sobre la extrafiscalidad ambiental en Brasil. Revista Fórum de Direito Financeiro e Econômico: RFDFE, Belo Horizonte, v. 2, n. 3, p. 13-27, mar./ago. 2013.

SCAFF, Fernando Facury. Orçamento republicano e liberdade igual: direito financeiro, república e direitos fundamentais. 2017. Tese (Titularidade para cargo de Professor Titular de Direito Financeiro) - Faculdade de Direito da Universidade de São Paulo, São Paulo, 2017.

SCAFF, Fernando Facury. Royalties do petróleo, minério e energia: aspectos constitucionais, financeiros e tributários. São Paulo: Revista dos Tribunais, 2014.

SCAFF, Fernando Facury; ATHIAS, Daniel Tobias. Dívida pública e desenvolvimento: do equilíbrio orçamentário à sustentabilidade financeira. In: POMPEU, Gina Marcilio; CARDUCCI, Michele; SÁNCHEZ, Miguel Revenga (Orgs.). Direito constitucional nas relações econômicas: entre o crescimento econômico e o desenvolvimento humano. Rio de Janeiro: Lumen Juris, 2014. p. 27-48.

SCAFF, Fernando Facury; SILVEIRA, Alexandre Coutinho da. Competência tributária, transferências obrigatórias e incentivos fiscais. In: CONTI, José Maurício; SCAFF, Fernando Facury; BRAGA, Carlos Eduardo Faraco (Coords.). Federalismo fiscal: questões contemporâneas. Florianópolis: Conceito Editorial, 2010. p. 285-302. 
SCAFF, Luma Cavaleiro de Macêdo. O financiamento das unidades de conservação: a compensação financeira do SNUC como instrumento de proteção ao meio ambiente. In: SCAFF, Fernando Facury; ATHIAS, Jorge Alex (Coords.). Direito tributário e econômico aplicado ao meio ambiente e à mineração. São Paulo: Quartier Latin: 2009. p. 350-367.

SCHANTZ JR., Radford. Purpose and effects of a royalty on public land minerals. Resources Policy, v. 20, No. 1, p. 35-48, Mar. 1994.

SCHAPIRO, Mario Gomes. Repensando a relação entre estado, direito e desenvolvimento: os limites do paradigma rule of law e a relevância das alternativas institucionais. Revista de Direito GV, v. 6, n. 1, p. 213-252, jan./jun. 2010. Disponível em: <http://bibliotecadigital.fgv.br/ojs/index.php/revdireitogv/article/view/24216/22989>. Acesso em: 09 maio 2018.

SCHWARTZ, Bernard. O federalismo norte-americano atual: uma visão contemporânea. Tradução de Elcio Cerqueira. Rio de Janeiro: Forense Universitária, 1984.

SEMMEL, Bernard. The rise of free trade imperialism: classical political economy the empire of free trade and imperialism (1750-1850). New York: Cambridge University Press, 1970.

SERRA, Silvia Helena; ESTEVES, Cristina Campos. Mineração: doutrina, jurisprudência, legislação e regulação setorial. São Paulo: Saraiva, 2012.

SILVA, Almiro do Couto e. Comentário ao artigo 20. In: CANOTILHO, José Joaquim Gomes; MENDES, Gilmar Ferreira; SARLET, Ingo Wolfgang; STRECK, Lenio Luiz (Coords.). Comentários à Constituição do Brasil. São Paulo: Saraiva; Almedina, 2013. p. 712-725.

SILVA, Isabela Morbach Machado e. Direito financeiro e os fundos de exploração de recursos naturais não renováveis. 2017. 184 p. Dissertação (Mestrado) - Faculdade de Direito da Universidade de São Paulo, São Paulo, 2017.

SILVA, Lucas Emanuel da; SANTANA, José Ricardo de; FARIAS, Tácito Augusto. Impacto das rendas petrolíferas sobre os municípios: uma análise das finanças públicas e desenvolvimento em Sergipe. Revista de Desenvolvimento Econômico: RDE, Salvador, BA, v. 16, n. 29, p. 76-91, dez. 2014. Disponível em:

<http://www.revistas.unifacs.br/index.php/rde/article/download/2946/2336>. Acesso em: 25 abr. 2018.

SILVA, Marcelo Squinca da. A política do setor elétrico nos anos dourados: embates entre paulistas e mineiros no processo de expansão do setor de energia elétrica no Brasil (19511961). São Paulo: Alameda, 2018.

SILVA, Maria Amélia Rodrigues da. Royalties da mineração: instrumento de promoção do desenvolvimento sustentável nas regiões mineradoras na Amazônia oriental? Cadernos do IG/UNICAMP, Campinas, v. 8, n. 1/2, p. 3-21, 2000. Disponível em:

$<$ http://repositorio.ufpa.br/jspui/bitstream/2011/3086/1/Artigo_RoyaltiesMineracaoInstrum ento.pdf>. Acesso em: 07 fev. 2018. 
SILVEIRA, Alexandre Coutinho da. Governança pública de royalties: federalismo fiscal e futuras gerações. Rio de Janeiro: Lumen Juris, 2016.

SILVEIRA, Alexandre Coutinho da; ATHIAS, Daniel Tobias. A finalidade da CFEM. Valor Econômico, Legislação, São Paulo, 21 dez. 2015.

SILVEIRA, Reynaldo Andrade da. A compensação financeira: receita tributária ou patrimonial?: algumas questões. In: SCAFF, Fernando Facury (Coord.). Ordem econômica e social: estudos em homenagem a Ary Brandão de Oliveira. São Paulo: LTr, 1999. p. 331336.

SOARES, Márcia Miranda. Federalismo e desigualdades sociais no Brasil atual. Revista Brasileira de Estudos Constitucionais: RBEC, Belo Horizonte, v. 5, n. 19, p. 143-175, jul./set. 2011.

SOLER, Jonathas Lima. Aspectos teóricos sobre os principais desafios à segurança alimentar e nutricional em comunidades afetadas pela atividade minerária de grande escala. Revista Fórum de Direito Financeiro e Econômico: RFDFE, Belo Horizonte, v. 4, n. 6, p. 223-235, set./fev. 2014/2015.

SOUSA, Rubens Gomes de. Petrobras - Sociedade de economia mista. Monopólio. Imunidade e isenção tributárias. Pessoas jurídicas de direito público e de privado. Revista de Direito Administrativo, Rio de Janeiro, v. 54, p. 474-491, mar. 1958. Disponível em: <http://bibliotecadigital.fgv.br/ojs/index.php/rda/article/view/18569/17614>. Acesso em: 12 mar. 2018.

SOUZA, Marcelo Mendo Gomes de. A compensação financeira pela exploração dos recursos minerais - CFEM. In: SOUZA, Marcelo Mendo Gomes de (Coord.). Direito minerário aplicado. Belo Horizonte: Mandamentos, 2003. p. 195-220.

SQUEFF, Flávia de Holanda Schmidt; NEGRI, Fernanda de. Ciência e tecnologia de impacto: uma análise do caso Darpa. In: RAUEN, André Tortato (Org.). Políticas de inovação pelo lado da demanda no Brasil. Brasília: IPEA, 2017. p. 413-442. Disponível em:

<http://www.ipea.gov.br/portal/images/stories/PDFs/livros/livros/20170705_politicas_de_i novacao.pdf $>$. Acesso em: 10 mar. 2018.

STEELE, Henry. Natural resource taxation: resource allocation and distribution implications. In: MASON, Gaffney (Ed.). Extractive resources and taxation. Madison: University of Winsconsin Press, 1967. p. 233-267.

STEPHAN, Paul B. Guerras fiscais nos Estados Unidos. In: DERZI; Misabel Abreu Machado; BATISTA JÚNIOR, Onofre Alves; MOREIRA, André Mendes (Orgs.). Estado Federal e guerra fiscal no direito comparado. Belo Horizonte: Arraes Editores, 2015. p. 161-170. 
SUSSKIND, Lawrence. Revenue sharing and the lessons of the new federalism. Urban Law Annual: Journal of Urban and Contemporary Law, v. 8, p. 33-71, Jan. 1974.

Disponível em:

<https://openscholarship.wustl.edu/cgi/viewcontent.cgi?article=1717\&context=law_urbanl aw>. Acesso em: 10 abr. 2018.

TARR, G. Alan. United States of America. In: KINCAID, John; TARR, G. Alan (Eds.). Constitutional origins, structure, and change in federal countries. London: McGillQueen's University Press, 2005. (A Global Dialogue on Federalism, v. 1).

TORRES, Heleno Taveira. Constituição financeira e o federalismo financeiro cooperativo equilibrado brasileiro. Revista Fórum de Direito Financeiro e Econômico: RFDFE, Belo Horizonte, v. 3, n. 5, p. 25-54, mar./ago. 2014.

TORRES, Heleno Taveira. Direito constitucional financeiro: teoria da constituição financeira. São Paulo: Revista dos Tribunais, 2014.

TORRES. Ricardo Lobo. Curso de direito financeiro e tributário. 19. ed. rev. e atual. Rio de Janeiro: Renovar, 2013.

TRINDADE, Adriano Drummond Cançado. Royalties na mineração no direito comparado. In: SOUZA, Marcelo Mendo Gomes de. A compensação financeira pela exploração dos recursos minerais: CFEM. Belo Horizonte: Del Rey, 2011. p. 71-86.

VARGAS, Getúlio. A nova política do Brasil: da aliança liberal às realizações do primeiro ano de governo, 1930-1931. Rio de Janeiro: José Olympio, 1938. v. 1.

VIARD, Alan D. (Ed.). Tax policy lessons from the 2000s. Washington DC: The AEI Press, 2009.

WEISMAN, Steven R. The great tax wars: Lincoln - Teddy Roosevelt - Wilson: how the income tax transformed America. New York: Simon \& Schuster; Paperback, 2004.

WEISS, Edith Brown. In fairness to future generations: international law, common patrimony, and intergenerational equity. Tokyo: The United Nations University, 1989.

WILLIAMS III, Roberton. A response to Gilbert E. Metcalf. In: VIARD, Alan D. (Ed.). Tax policy lessons from the 2000s. Washington DC: The AEI Press, 2009. p. 35-44.

WILLIAMS III, Roberton. Environmental taxation. In: AUERBACH, Alan J.; SMETTERS, Kent. The economics of tax policy. New York: Oxford University Press, 2017. p. 49-73.

WISEMAN, Hannah J. Urban Energy. Fordham Urban Law Journal. v. 40, No. 5, p. 1.793-1.833, 2013. Disponível em: <https://ir.lawnet.fordham.edu/ulj/vol40/iss5/13/>. Acesso em: 15 mar. 2018. 
WOODGERD, David; MCCARTHY, Bernard F. State school trust lands and oil and gas royalty rates. Public Land and Resources Law Review, v. 3, p. 119-132, 1982. Disponível em: <https://scholarship.law.umt.edu/cgi/viewcontent.cgi?article=1067\&context=plrlr $>$. Acesso em: 18 abr. 2018.

WORLD BANK. World development report 1994: infrastructure for development. New York: Oxford University Press, 1994. Disponível em:

<https://openknowledge.worldbank.org/bitstream/handle/10986/5977/WDR\%201994\%20\%20English.pdf?sequence=2\&isAllowed=y >. Acesso em: 18 abr. 2018.

YOSHIDA, Consuelo Yatsuda Moromizato. A efetividade e a eficiência ambiental dos instrumentos econômico-financeiros e tributários: ênfase na prevenção: a utilização econômica dos bens ambientais e suas implicações. In: TORRES, Heleno Taveira (Org.). direito tributário ambiental. São Paulo: Malheiros, 2005. p. 527-564.

ZIMMERMAN, Joseph J; BULLERDICK, Kim H. Federal royalty oil eligibility requirements: the 'plateau' legacy. Natural. Resources Lawyer, v. 16, No. 4, p. 597-611, 1984. 